\title{
Relações educacionais entre 0 Design e a Engenharia: um panorama nacional e internacional
}

Claudia Alquezar Facca é Mestre e Doutora em Design pela Universidade Anhembi Morumbi; Especialista em Didática do Ensino Superior e em Comunicação e Artes pela Universidade Presbiteriana Mackenzie; Bacharel em Desenho Industrial com habilitação em Projeto de Produto pela Universidade Presbiteriana Mackenzie; docente nos Cursos de Design e Engenharia e Coordenadora dos Cursos de Graduação e Pós-Graduação em Design do Centro Universitário do Instituto Mauá de Tecnologia.

<claudiafacca01@gmail.com> ORCID: 0000-0003-0113-5516
Resumo Este artigo sintetiza uma parte da tese de doutorado intitulada "A contribuição do pensamento do Design na formação do Engenheiro: o espaço do Fab Lab como experiência transversal" e apresenta como objeto de estudo uma análise comparativa referente à inserção do ensino de Design nos cursos superiores de Engenharia, em um panorama nacional (no Brasil) e internacional (em outros países). Foi realizada uma investigação exploratória e descritiva dividida em duas etapas. Primeiramente foi feito um levantamento de como o Design está sendo inserido nos cursos de graduação em Engenharia e depois, foi pesquisado como o Design e a Engenharia estão convivendo em cursos integrados; nos dois casos estão sendo considerados os panoramas nacionais e internacionais. A pesquisa teve uma função importante para a visualização da situação atual da educação em Engenharia e foi fundamental para se perceber a lacuna existente e quantas oportunidades e espaços ainda existem para serem explorados.

Palavras chave Design, Engenharia, Educação, Panorama Mundial. 
Ana Mae Barbosa é Professora Titular Senior na ECA/USP e na Universidade Anhembi Morumbi. Ensinou na Yale University e na The Ohio State University. Tem 23 livros publicados. Recebeu vários prêmios nacionais e internacionais por suas pesquisas: a Ordem Nacional do Mérito Cientifico, a Ordem Nacional do Mérito Cultural e o Itaú Cultural 30 anos. Foi presidente da INSEA, da ANPAP e Diretora do Museu de Arte Contemporânea da USP. <anamaebarbosa@gmail.com > ORCID: 0000-0002-4966-2043

Jorge Lino Alves é Engenheiro Mecânico, PhD em Ciência dos Materiais, Professor Associado da FEUP (Faculdade de Engenharia da Universidade do Porto), Porto, Portugal. Diretor FEUP do Mestrado em Design Industrial e de Produto (UP), Diretor do DESIGNSTUDIO FEUP e Laboratório de Desenvolvimento de Produto e Serviços, Presidente da Sociedade Portuguesa de Materiais (SPM). Desenvolve investigação na área do desenvolvimento de produto e fabrico aditivo. Coautor de 3 livros, 140 comunicações em eventos científicos, 140 artigos em revistas e capítulos de livros, 215 artigos em conferências, um registro de desenho ou modelo comunitário, 65 posters, 6 vídeos acerca de inovação tecnológica, e tem 21 prêmios em concursos. <falves@fe.up.pt > ORCID: 0000-0002-9327-9092

\section{Educational relations between Design and Engineering: a national and international panorama}

Abstract This paper summarizes a part of the doctoral thesis entitled "The contribution of design thinking in the formation of the engineer: the Fab Lab space as a transversal experience" and presents as object of study a comparative analysis referring to the insertion of design teaching in higher engineering courses, in a national (in Brazil) and international (in other countries) panorama. An exploratory and descriptive investigation was carried out divided into two stages. First, a survey was made of how Design is being inserted in undergraduate engineering courses and then it was researched how Design and Engineering are living in integrated courses; in both cases are being considered the national and international panoramas. The research had an important function for visualizing the current situation of engineering education and was fundamental to understand the existing gap and how many opportunities and spaces still exist to be explored.

Keywords Design, Engineering, Education, World Panorama.

\section{Relaciones educativas entre Diseño e Ingeniería: un panorama nacional e internacional}

Resumen Este artículo resume una parte de la tesis doctoral titulada "La contribución del pensamiento de diseño en la formación del ingeniero: el espacio de Fab Lab como experiencia transversal" y presenta como objeto de estudio un análisis comparativo que se refiere a la inserción de la enseñanza de diseño en cursos de ingeniería superior, en un panorama nacional (en Brasil) e internacional (en otros países). Se llevó a cabo una investigación exploratoria y descriptiva dividida en dos etapas. En primer lugar, se hizo una encuesta de cómo se inserta el diseño en los cursos de ingeniería de grado y luego se investigó cómo el diseño y la ingeniería viven en cursos integrados; en ambos casos se están considerando los panoramas nacionales e internacionales. La investigación tenía una función importante para visualizar la situación actual de la educación en ingeniería y era fundamental para comprender la brecha existente y cuántas oportunidades y espacios aún existen para ser explorados.

Palabras clave Diseño, Ingeniería, Educación, Panorama Mundial. 


\section{Introdução}

As sociedades estão mudando rápida e profundamente e têm demandado novas soluções para um mundo em constante transformação, onde diversos desafios têm sido apresentados nos âmbitos econômico, social e ambiental (OECD, 2018; NESTERIUK e INGS, 2018). A educação tem sido objeto de estudo, preocupação, foco, estratégia e discussão em todas as nações do globo e reflete as intensas mudanças que o mundo testemunhou nas últimas décadas do século XX, começando com as duas grandes guerras e depois com a expansão do capitalismo e a globalização cultural e econômica no século XXI (FACCA, ALVES e BARBOSA, 2019a).

Os tempos mudaram e uma enorme infraestrutura de comunicação e colaboração tem ajudado a resolver problemas complexos utilizando o desenvolvimento de esforços em larga escala entre pesquisadores de disciplinas díspares. Envoltos nessa natureza dinâmica, os currículos de ensino devem ser projetados de maneira a ajudar a desenvolver nos alunos habilidades de pensamento crítico e de resolução de problemas nas principais disciplinas e nos novos conteúdos orientados por tecnologia e inseridos em contextos multi, inter e transdisciplinares. Tanto a inter como a transdisciplinaridade fornecem soluções integradas para um problema em questão (FACCA, 2020). Entretanto a pesquisa transdisciplinar inclui os principais componentes da interdisciplinaridade, juntamente com a incorporação de conhecimento não acadêmico externo, aplicado para resolver problemas práticos, levando à criação de novos paradigmas e fornecendo caminhos para cruzar novas fronteiras (ERTAS, 2012, p. 29). "Os alunos precisam aprender novas habilidades para sintetizar dinamicamente novos conhecimentos em resposta a novos desafios".

\section{0 ensino de Engenharia}

A necessidade de mudança no ensino superior e a promoção da inter e da transdisciplinaridade estimulam o empreendedorismo, enfatizam o envolvimento cultural e social das universidades na construção de um sistema educacional superior, impulsionado por um investimento estratégico do governo no ensino de Engenharia como uma incubadora de talentos empresariais de base tecnológica (BRASIL, 2019; CNI, 2018; GRAHAM, 2018; MAGALHÃES, 2014). Nos últimos duzentos anos a Engenharia tem enfrentado muitos desafios que vão desde a eficiência da produção, a redução de custos, a melhoria de qualidade, controles de poluição e preocupações com segurança até a automação, informatização, miniaturização, integração de sistemas complexos e restrições de recursos, entre outros (ERTAS, 2018). Tais desafios estão contemplados em uma estrutura disciplinar em evolução e expansão cuja demanda tem exigido uma performance que vem influenciando praticamente todos os aspectos da vida moderna. Embora as 
abordagens multidisciplinares e interdisciplinares desenvolvidas inicialmente tenham produzido resultados interessantes, o foco sempre foi o artefato como um sistema complexo e não como parte de um sistema adaptativo complexo. Com as mudanças atuais, fruto da globalização, estão sendo demandados não apenas mais engenheiros, mas também novas formas de colaboração e integração, considerando agora o todo e abordando diretamente o projeto complexo de sistemas adaptativos. "A educação em Engenharia deve produzir um novo tipo de engenheiro, que rompa as barreiras do pensamento disciplinar. A transdisciplinaridade deve se tornar parte integrante do futuro dessa venerável profissão" (ERTAS et al., 2007, p. 6).

O ensino de Engenharia ocupa um lugar central nas discussões que envolvem a formulação e implementação de estratégias para o desenvolvimento industrial. Faz parte do leque de desafios que os países devem enfrentar para sustentar ganhos de produtividade e fortalecer suas posições competitivas, proporcionando uma economia mundial baseada no conhecimento mais dinâmico, capaz de promover um crescimento econômico duradouro (BRASIL, 2019; CNI, 2018; GRAHAM, 2018; MAGALHÃES, 2014).

Em função da natureza dos sistemas de Engenharia modernos, as abordagens disciplinares tradicionais se mostraram insuficientes e estratégias complementares estão sendo exploradas por pesquisadores e educadores. Nesse sistema, os produtos tornaram-se integrados e os requisitos de projeto e produção ultrapassam tais fronteiras, o que requer a contribuição de várias disciplinas da Engenharia, bem como de outras disciplinas como negócios, ciências sociais, biológicas, etc. Com a aceleração do desenvolvimento de novos sistemas técnicos a demanda passou de equipes de projeto multi ou interdisciplinares para um trabalho transnacional ${ }^{1}$ e transorganizacional $^{2}$. (ERTAS et al., 2007).

O conceito de Engenharia deriva do início da história da humanidade, à medida que nossos ancestrais desenvolviam e projetavam ferramentas essenciais para sua sobrevivência. A Engenharia é uma das profissões mais antigas, juntamente com a Medicina e o Direito (UNESCO, 2010). Há muitas definições de Engenharia.

Engenharia é o campo ou disciplina, prática, profissão e arte que se relaciona ao desenvolvimento, aquisição e aplicação de conhecimentos técnicos, científicos e matemáticos sobre o entendimento, projeto, desenvolvimento, invenção, inovação e uso de materiais, máquinas, estruturas, sistemas e processos para fins específicos (UNESCO, 2010, p. 24). 
A ABET - Accreditation Board for Engineering and Technology define a Engenharia como:

A profissão na qual o conhecimento das ciências matemáticas e naturais, adquirido por meio de estudo, experiência e prática é aplicado com julgamento para desenvolver maneiras de utilizar, economicamente, os materiais e forças da natureza para o benefício da humanidade (ABET, 1986).

Outras definições mais atuais de Engenharia englobam desde o seu entendimento como "uma ciência que estuda as transformações de recursos naturais e tecnológicos para o desenvolvimento de benefícios para a humanidade" até a visão da Engenharia como "a aplicação de conhecimento científico e tecnológico para a solução de problemas, por meio de projetos para a viabilização de produtos (bens e serviços) e novos empreendimentos" (OLIVEIRA, 2019c, p. 9).

Apesar de os conceitos relacionados à Engenharia estarem relacionados principalmente à tecnologia e às ciências exatas, sua natureza está ligada também a outros termos como arte e técnica, ciências naturais, humanas e sociais, uma vez que os seres humanos vivem em economias, sociedades e tecnoculturas associadas a algum ramo da Engenharia. A profissão de engenheiro, como em outras profissões, é uma vocação ou ocupação baseada em educação e treinamento especializados, relacionados a disciplinas específicas e a um conjunto de habilidades técnicas associadas que incluem abordagens lógicas e práticas de resolução de problemas além de habilidades socioemocionais como motivação, rápida compreensão, comunicação e liderança. Os engenheiros usam tanto o conhecimento científico quanto a matemática para criar tecnologias e infraestrutura, por um lado, e para abordar questões humanas, sociais e econômicas, por outro. Os engenheiros conectam necessidades sociais com inovação e aplicações comerciais (UNESCO, 2010).

No final do século XIX, a maioria dos países, agora industrializados, estabeleceram seus próprios sistemas de ensino de Engenharia com base no modelo de educação superior chamado Humboldtian, criado pelo alemão Alexander von Humboldt. A ideia central deste modelo era baseada numa combinação holística entre pesquisas e estudos, integrando as artes e as ciências à pesquisa para alcançar um aprendizado geral abrangente e um conhecimento cultural. Este modelo linear de inovação, que influenciou a organização dos cursos de Engenharia mundo afora e ainda é seguido até hoje, apesar de ter sido o primeiro e maior modelo conceitual a relacionar a ciência, a tecnologia e o desenvolvimento econômico, está baseado na noção de que a pesquisa científica básica e pura, seguida pelo desenvolvimento aplicado, leva a produção e difusão do conhecimento (UNESCO, 2010). O modelo de separação entre o básico (período de ingresso que dura em 
média dois anos) e o profissionalizante (que permite a escolha da área da Engenharia após a conclusão do ciclo básico) só começou a ser substituído no final do século XX, mas ainda perdura em várias instituições até hoje (OLIVEIRA, 2019c).

A educação em Engenharia tem a necessidade de superar esta abordagem "fundamental" do modelo linear de inovação, e se posicionar de maneira mais eficaz numa aprendizagem baseada em problemas, concentrando-se especificamente no seu importante papel como parte da solução aos grandes problemas da humanidade, como os 17 Objetivos de Desenvolvimento Sustentáveis propostos pela Organização das Nações Unidas - ONU (UNESCO, 2010).

Em 2018, foram registrados 6.106 cursos de Engenharia no sistema e-MEC (Portal do Ministério da Educação), operando em 1.176 instituições distintas, incluindo educação privada e pública, nas modalidades presencial e à distância. Além da expansão numérica, houve também um grande crescimento de qualificações ou áreas de cobertura dos cursos de Engenharia. Hoje já são 60, considerando a primeira denominação dos cursos (civil, elétrica, mecânica, etc.) e mais de 250 quando é considerada a segunda denominação ou ênfase (construção civil, energia elétrica, mecânica automobilística, etc.). Desde a publicação da Resolução CNE/CES nº 11, de 11 de março de 2002, que estabeleceu as Diretrizes Curriculares Nacionais para o Curso de Graduação em Engenharia, verificou-se a maior expansão em termos de número de cursos e de áreas de abrangência da Engenharia. Entre $2001 \mathrm{e}$ 2018 , houve, portanto, um crescimento total de $692 \%$ no número de cursos de Engenharia no Brasil (BRASIL, 2019).

De 2010 a 2014, devido principalmente ao desempenho do País em termos de expansão de infraestruturas, registrou-se um crescimento significativo, tanto em termos de ofertas (consequência da expansão do número de cursos oferecidos) quanto candidaturas nos cursos de Engenharia (CNI, 2018; BRASIL, 2019). Mas esses números estão diminuindo devido à recente crise econômica, política e social que o Brasil vive. Sobre a evolução do alunado dos cursos de Engenharia observa-se que o número de matriculados em programas de Engenharia teve um crescimento até 2015, atingindo o expressivo número de 1,4 milhão de matriculados. No ano seguinte, iniciou-se uma queda, alcançando-se 1,09 milhão de matriculados em 2017, número inferior ao que existia em 2013. Enquanto o número de cursos só cresceu no período, o número de alunos matriculados passou a cair a partir de 2015 (NITZ e LEONI, 2019). Em 2018, segundo dados do Instituto Nacional de Estudos e Pesquisas Educacionais Anísio Teixeira - INEP, o número de alunos matriculados nos cursos presenciais de Engenharia, Produção e Construção no Brasil era de 1.073.782 (INEP/MEC, 2019).

Dados do INEP, sistematizados pela Associação Brasileira de Educação em Engenharia (ABENGE), revelam que, numa estimativa de evasão representativa, para cada 1.000 candidatos inscritos em processos de seleção de Engenharia, 175 se matricularam e apenas 95 concluíram seus cursos, 
sugerindo uma espécie de "funil" na formação de engenheiros no Brasil. As avaliações dos cursos superiores, realizados pelo INEP, também são sugestivas das fragilidades da educação em Engenharia no país: de 1.538 cursos avaliados em 2014, cerca de 60 \% atingiram a pontuação mínima satisfatória e $15 \%$ ficaram abaixo desse valor (CNI, 2018).

O Brasil tem enfrentado algumas dificuldades para competir no mercado internacional. De acordo com o Índice Global de Inovação (IGI), o país perdeu 22 posições no ranking entre 2011 e 2016, ficando em $69^{\circ}$ lugar entre os 128 países avaliados, posição em que se manteve até 2017. O fraco desempenho brasileiro deve-se, entre outros fatores, à baixa pontuação obtida no indicador relacionado a recursos humanos e pesquisas, que se refere aos graduados em Engenharia (BRASIL, 2019). O Brasil, segundo a OECD (2016), ocupou uma das últimas posições no ranking. Em 2014, o Brasil registrou apenas 4,8 engenheiros para cada 10 mil habitantes enquanto países como Coreia do Sul, Rússia, Finlândia e Áustria contavam com mais de 20 engenheiros para cada 10 mil habitantes (OLIVEIRA, 2019c).

Diante do lugar central ocupado pela Engenharia na geração de conhecimentos, tecnologias e inovações, é estratégico considerar essas novas tendências e enfatizar a melhoria da qualidade dos cursos oferecidos no país, a fim de aumentar a produtividade e a expansão das possibilidades de crescimento econômico, tanto hoje como no futuro. Como resultado, a recente revisão das Diretrizes Curriculares Nacionais dos Cursos de Engenharia é uma parte fundamental desse processo (BRASIL, 2019; FACCA, ALVES e BARBOSA, 2019a)

A criação do Conselho Nacional de Educação - CNE (1985/1986), que estabeleceu as Diretrizes e Bases da Educação Nacional, inovou ao eliminar do cenário de regulação dos cursos de graduação o conceito de "currículo mínimo", introduzindo o novo conceito de diretrizes curriculares (OLIVEIRA, 2019a). As diretrizes curriculares são normas que orientam o projeto e o planejamento de um curso de graduação (BRASIL, 2019). As diretrizes curriculares enquanto são flexíveis e com ênfase generalista se contrapõem à especialização precoce e à artificialidade das múltiplas habilitações do currículo mínimo - essencialmente único, prescritivo, detalhado e rígido, que admitia pouquíssimas variações (OLIVEIRA, 2019a).

As primeiras Diretrizes Curriculares Nacionais (DCN) do Curso de Graduação em Engenharia foram estabelecidas pela Resolução CNE/CES nº11/2002, mais de 25 anos após a criação do currículo mínimo em 1976, já tratando de competências e habilidades gerais, de conteúdos curriculares de forma ampla, de algumas orientações metodológicas e da importância da avaliação da aprendizagem e do curso. Entretanto foram realizadas mais adaptações ao modelo vigente do que inovações de fato (OLIVEIRA, 2019a). E quase 18 anos depois, num cenário de profundas transformações nos meios de produção e do trabalho, em que se discute amplamente a formação de engenheiros no Brasil e no mundo, foi homologada a sua nova versão em 2019, colocando o estudante no centro do processo de aprendizagem e 
como agente de conhecimento, estimulando a modernização e a atualização contínua dos cursos, uma maior integração entre empresa e escola, a valorização da inter e da transdisciplinaridade, além do professor como agente condutor das mudanças necessárias (BRASIL, 2019).

Segundo Oliveira (2019a) a maior diferença entre as duas resoluções provavelmente está no artigo $4^{\circ}$ que estabelece como objetivo o desenvolvimento de competências e não apenas fornecimento de elementos para posterior desenvolvimento, sendo os projetos dos cursos formulados não mais em função dos conteúdos, mas com foco na formação do engenheiro como inovador, empreendedor e também professor (BRASIL, 2019). De acordo com a Resolução CNE/CES № 2, de 24 de abril de 2019 (BRASIL, 2019), tais competências são:

- Formular econceber soluções desejáveis deEngenharia, analisando e compreendendo a necessidade dos usuários e seu contexto;

- Analisar e compreender os fenômenos físicos e químicos por meio de modelos simbólicos, físicos e outros, uma vez verificados e validados por experimentação;

- Conceber, projetar e analisar sistemas, produtos (bens e serviços), componentes ou processos;

- Implantar, supervisionar e controlar as soluções de Engenharia;

- Comunicar-se eficazmente nas formas escrita, oral e gráfica;

- Trabalhar e liderar equipes multidisciplinares;

- Conhecer e aplicar com ética a legislação e os atos normativos no âmbito do exercício da profissão;

- Aprender de forma autônoma e lidar com situações e contextos complexos, atualizando-se em relação aos avanços da ciência, da tecnologia, bem como em relação aos desafios da inovação.

Outras mudanças importantes propostas também na nova resolução são a respeito da substituição da "sala de aula" por um "ambiente de aprendizagem", o que segue alinhado ao ensino por competências e a adoção de metodologias ativas de aprendizagem ativas, e a atualização do perfil do egresso, inserindo uma visão holística, a aptidão para a pesquisa, a atuação inovadora e empreendedora, a atenção ao usuário, além da preocupação com a cidadania e a sustentabilidade, necessárias à formação atual em Engenharia (OLIVEIRA, 2019b). 
Uma das inovações das DCN do Curso de Graduação em Engenharia é a possibilidade de explicitar a atuação do engenheiro tanto como projetista de soluções inovadoras, quanto como empreendedor. 0 desenvolvimento do perfil e das competências estabelecidas para o egresso pressupõem a atuação "em todo o ciclo de vida e contexto do projeto de produtos (bens e serviços) e de seus componentes, sistemas e processos produtivos, inclusive inovando-os" (BRASIL, 2019, p. 26). As diretrizes curriculares nacionais devem encerrar necessariamente certa flexibilidade para se adequar aos diversos contextos espaciais e temporais, sem tolher, no entanto, a melhoria contínua ou a inserção de inovações decorrentes, por exemplo, de novas tecnologias e metodologias devendo, ao contrário servir de incentivo a essas ações inovadoras (BRASIL, 2019).

A fim de contribuir com a epistemologia da Engenharia, Figueiredo (2008) propõe que esta seja considerada sob quatro dimensões: 1) Ciências Básicas - engenheiro como cientista; 2) Ciências Sociais - engenheiro como "especialista social"; 3) Design - engenheiro como designer; e 4) Realização Prática - engenheiro como "fazedor". Ao se considerar a associação das quatro dimensões como um exercício de transdisciplinaridade, a Engenharia poder ser resultante da mútua interpenetração dessas quatro dimensões num sistema de produção de conhecimento ligado de forma contínua, configurado especificamente e fortemente orientado pela solução de problemas. E o Design pode contribuir de forma desafiadora já que o engenheiro atuando como designer valorizaria o pensamento sistêmico mais do que o analítico e se basearia em visões holísticas, contextuais, transversais e integradas do mundo. A proposta de inserção de temas transversais, como o Design, traz à tona a necessidade de reflexão sobre novos valores e atitudes que possam ser desenvolvidos em diversas disciplinas, fazendo parte do currículo da Engenharia, por exemplo.

A transversalidade é entendida como uma forma de organizar o trabalho didático-pedagógico em que temas e eixos temáticos são integrados às disciplinas e às áreas ditas convencionais, de forma a estarem presentes em todas elas. A transversalidade difere da interdisciplinaridade e ambas se complementam, rejeitando a concepção de conhecimento que toma a realidade como algo estável, pronto e acabado. A transversalidade refere-se à dimensão didático-pedagógica, e a interdisciplinaridade, à abordagem epistemológica dos objetos de conhecimento (BRASIL, 2010).

Dym (2005) destaca a necessidade de mudanças nos cursos de Engenharia que poderiam se beneficiar da aplicação dos preceitos da teoria do Design e da análise de sistemas. Segundo o autor, os princípios de Design podem ajudar a moldar os objetivos da formação em Engenharia e identificar funções que lhes permitam atingir e avaliar esses objetivos. $O$ engenheiro "renascido" no século XXI deve ser um identificador, avaliador, criador e solucionador de problemas, trabalhando com pessoas de outras áreas científicas, artísticas ou técnicas e de diferentes culturas; deve combinar conhecimento e habilidades técnicas com liderança, empreendedorismo e habilidades de ge- 
renciamento e relacionamento; deve conhecer o contexto técnico, político e comercial do produto de seu trabalho, preocupando-se com a sustentabilidade econômica, social e ambiental; deve se comportar de forma ética e desenvolver habilidades de cidadania global (MAGALHÃES, 2014).

No estudo realizado pelo MIT sobre "O estado global da arte na educação em Engenharia" (GRAHAM, 2018), foram antecipadas três principais tendências sobre o futuro da educação em Engenharia. São elas: 1) Inversão da liderança destacando a mudança do hemisfério norte para o hemisfério sul e dos países de alta renda para às emergentes potências econômicas da Ásia e América do Sul; 2) Mudança em direção ao currículo socialmente relevante e voltado para o exterior, enfatizando a escolha do aluno, a aprendizagem multidisciplinar e o impacto social, juntamente com uma ampla experiência fora da sala de aula, além das disciplinas de Engenharia tradicionais e ao redor do mundo; e 3) Surgimento de uma nova geração de líderes que oferece currículos integrados, centrados no aluno, onde a coerência e a integração curricular são proporcionadas por meio de uma "espinha dorsal" conectiva de projetos de Design multidisciplinares, que contextualizam e integram a aprendizagem através de cursos e anos de estudo.

\section{0 pensamento do Design}

No cenário de competição global, as empresas passaram a perceber que já não bastava oferecer apenas superioridade tecnológica ou excelência em desempenho como vantagem mercadológica (BROWN, 2009; VIANNA et al., 2012). Com a expansão do Design em novas fronteiras, os limites do que é e o que não é Design estão ficando cada vez mais incertos. Os designers, ao se tornarem defensores dos usuários e clientes nas organizações, têm se esforçado para elevar o papel do Design, avançando no processo de decisão até alcançar a área executiva das empresas (BJÖRKLUND e KEIPI, 2019).

Foi buscando novos caminhos para a inovação que se cunhou o que hoje é conhecido como "Design Thinking" ou "Pensamento de Design": "uma abordagem focada no ser humano que vê na multidisciplinaridade, colaboração e tangibilização de pensamentos e processos, caminhos que levam a soluções inovadoras para negócios" (VIANNA et al., 2012, p. 12). O Design Thinking é uma abordagem centrada no usuário para a resolução criativa de problemas e inovação (BROWN, 2009; MICHELI et al., 2018; VIANNA et al., 2012). A evolução do Design para o Design Thinking parte inicialmente da criação de produtos, passa pela relação entre pessoas e produtos até chegar ao relacionamento entre pessoas e pessoas (BROWN, 2009). As metodologias de Design são, sem dúvida, parte do Design Thinking, mas não são a mesma coisa. O Design Thinking é uma força colaborativa que agrupa as disciplinas numa visão mais ampla e holística e não se limita a viver apenas dentro da disciplina de Design", conforme apresentado na Figura 1 (BRAUTIGAM, 2017). 
Fig 1. Relação entre o Design e o Design Thinking | Fonte: Adaptado pelos autores (BRAUTIGAM, 2017)

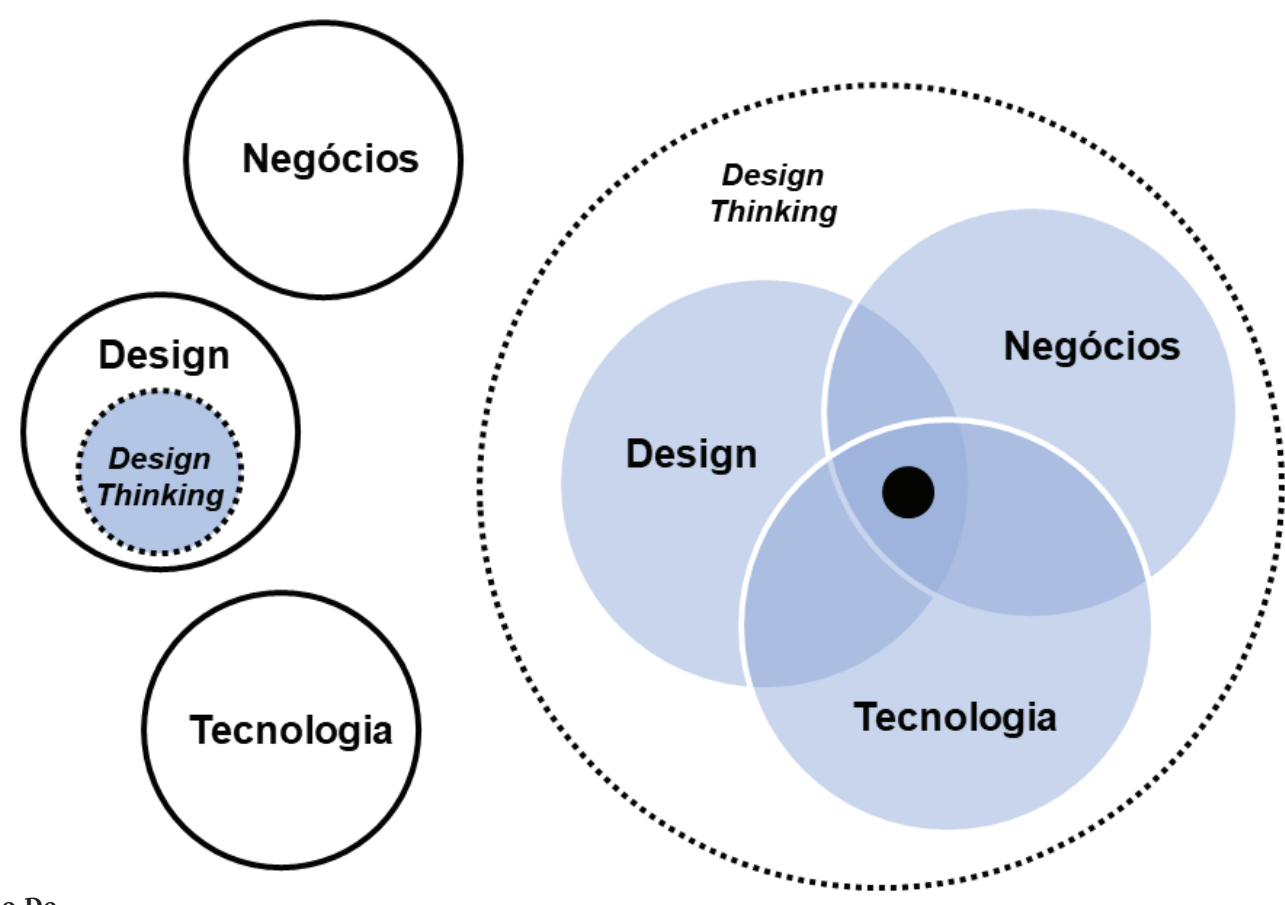

Muitas vezes é creditada à $\mathrm{IDEO}^{3}$ a invenção do termo "Design Thinking" e sua aplicação prática. Mas o Design Thinking tem raízes mais profundas que vêm se desenvolvendo há décadas em uma conversa ampla e global. A IDEO vem praticando o Design centrado no ser humano para solucionar problemas em pequena ou grande escala desde a sua fundação, em 1978, quando começou a usar o termo "Design Thinking". E, juntamente com a Stanford Design School (d.school), tem sido uma das principais responsáveis pela difusão e fortalecimento do Design em todo o mundo (IDEO, 2020).

Apesar de não existir uma definição única o Design Thinking é uma ideia, uma estratégia, um método e uma maneira de ver o mundo; uma maneira de resolver problemas por meio da criatividade. De acordo com Tim Brown, Presidente Executivo da IDEO “o Design Thinking é uma abordagem para a inovação centrada no ser humano, que parte das ferramentas do designer para integrar as necessidades das pessoas, as possibilidades da tecnologia e os requisitos para o sucesso do negócio". Essa abordagem reúne o que é desejável do ponto de vista humano (desirability ou "desejabilidade") com o que é tecnologicamente viável (feasibility ou factibilidade) e economicamente viável (viability ou viabilidade) (IDEO, 2020).

o Design Thinking começa com "as habilidades que os designers aprenderam ao longo de várias décadas em sua busca para atender às necessidades humanas com os recursos técnicos disponíveis, dentro das restrições práticas dos negócios" (BROWN, 2009, p. 10). Ao colocar suas ferramentas nas mãos de pessoas que talvez nunca tenham se considerado designers e aplicá-las a uma gama maior de problemas, o Design Thinking dá o próximo passo, quebrando paradigmas, abordando a inovação de for- 
ma eficaz e acessível, e integrando todos aspectos da sociedade. A mentalidade do designer engloba a empatia, o otimismo, a iteração, a criatividade e a ambiguidade, mantendo as pessoas no centro de todos os processos e estimulando o pensamento divergente (para criar oportunidades) e convergente (para fazer escolhas) (IDEO, 2020).

Não há um roteiro ou uma sequência ordenada de etapas para aplicar o Design Thinking. 0 que existem, segundo a IDEO (2020), são pontos de partida e de referência importantes ao longo do caminho. Pode-se pensar nesses pontos resumidos em três atividades principais: 1) a inspiração, o problema ou oportunidade que motiva a busca de soluções; 2) a ideação, o processo de geração, desenvolvimento e teste de ideias; e 3) a implementação, o caminho que leva do projeto ao mercado. Sendo que os projetos podem voltar a percorrer esses espaços mais de uma vez, conforme o refinamento das ideias e a exploração de novas direções.

Se a IDEO é mais famosa em relação ao Design Thinking voltado aos negócios, a d.school no Instituto de Design Hasso Plattner na Universidade de Stanford é a principal referência do setor educacional (BJÖRKLUND e KEIPI, 2019). A d.school não procura educar designers tradicionais e, de fato, não oferece nem um curso de "Design". Em vez disso, serve como um ambiente único, onde estudantes em áreas distantes como Medicina, $\mathrm{Ne}$ gócios, Direito ou Engenharia podem se reunir para trabalhar em projetos de Design colaborativo e de interesse público. A d.school incentiva a pesquisa centrada no ser humano, o brainstorming e a criação de protótipos em todos os projetos, mas também aplica esses princípios fundamentais do Design Thinking a si própria: os espaços são dinâmicos, os rankings acadêmicos são irrelevantes, o currículo está em fluxo permanente - é, em suma, um protótipo contínuo do próprio processo educacional. o processo de Design da d.school é dividido em cinco módulos: 1) Empatia, para conhecer o público alvo; 2) Definição, das questões chaves; 3) Ideação, criação de soluções; 4) Prototipação, para construir e representar as ideias; e 5) Teste, das ideias e possíveis feedbacks dos usuários (D.SCHOOL, 2020).

O cenário em que se chegou passou de uma solidez moderna e estática para uma contemporaneidade imprevisível, repleta de códigos, de difícil compreensão, complexa, fluida e dinâmica, onde, segundo Moraes (2008, p. 12) "é necessário estimular e alimentar constantemente o mercado por meio da inovação e diferenciação pelo Design". Se formos definir uma teoria do Design, esta teria provavelmente constituição transdisciplinar, pois teria condições de combinar conhecimentos pertencentes a diversas áreas científicas e, através de suas práxis, poderia assumir o papel de elo conciliador ou interventor entre diferentes especialistas (BOMFIM, 2014; ZUANON, PRADO e FERREIRA, 2016). "No mundo sólido do passado, existiam containers disciplinares e seguros nos quais qualquer um poderia se posicionar. Agora não é mais assim: no mundo fluido contemporâneo os containers foram abertos e as suas paredes não são mais protegidas" (BERTOLA e MANZINI, 2004, p. 10-17). 
Hoje, é necessário que o processo de inserção desses valores em escala produtiva industrial seja, portanto, "projetável", de maneira que possibilite o aumento do significado do produto (conceito) e a sua significância (valor). Tudo isso exige e exigirá dos designers uma outra capacidade que vai além do aspecto projetual, uma capacidade permanente de atualização e de gestão da complexidade (MORAES, 2008, p. 13, 16).

\section{Desempenho (tecnologia)}

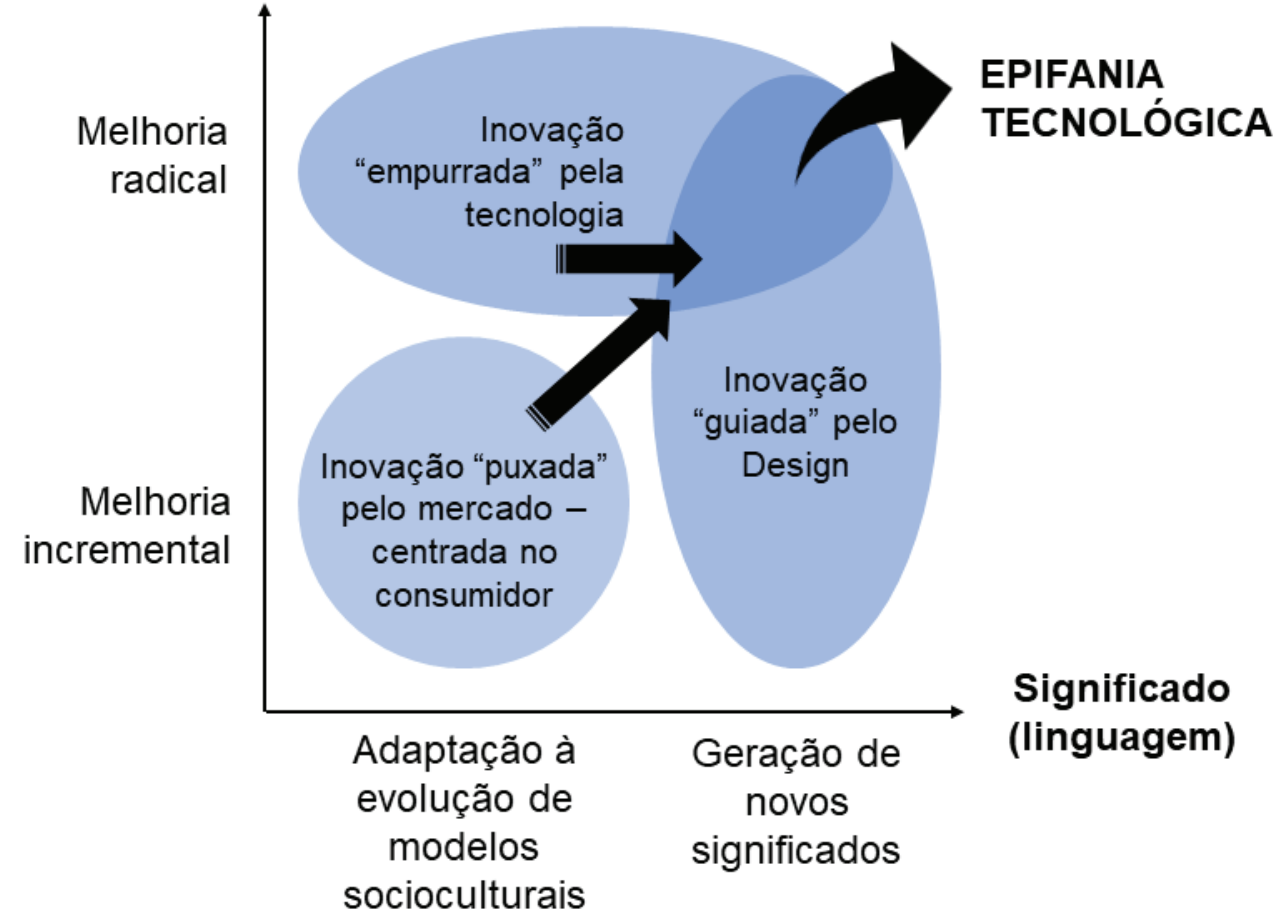

Fig 2. Epifania tecnológica: a interação entre a inovação "empurrada" pela tecnologia e a inovação "guiada" pelo design | Fonte: Adaptado pelos autores (VERGANTI, 2012, p. 61)

O Design tornou-se um tópico popular na literatura de gestão exposto a diversas interpretações: desde um conceito imediatista como estilo até uma concepção mais ampla como qualquer atividade criativa ou inovadora. Associar o Design à inovação em geral foi o $1^{\circ}$ passo para expandir a ideia de design apenas ligada à forma. Termos como Engenharia de Design são frequentemente utilizados para descrever a inovação com foco em tecnologia. Dessa forma, estratégias de inovação "guiadas" pelo Design têm se mostrado expressivas e sustentáveis, agregando valor às marcas e ajudando as empresas a crescer. A inovação tecnológica (desempenho) aliada à inovação do significado (linguagem), protagonizada pelo Design, faz uma grande diferença no desenvolvimento de novos produtos e serviços no mercado (VERGANTI, 2012). 
Verganti (2012, p. 65) chama de "epifania tecnológica" (Figura 2) a interação entre a inovação "empurrada" pela tecnologia (technology push) e a inovação "guiada" pelo Design (Design-driven), quando "uma tecnologia revolucionária traz também novos significados que estão esperando para serem descobertos". Considerar apenas um dos aspectos da estratégia de inovação, ou seja, o aspecto da inovação tecnológica, e não procurar pelos significados escondidos pode gerar comportamentos míopes.

o grande desafio na atualidade para o campo do Design é atuar em cenários considerados como fluidos, dinâmicos, mutantes e complexos. A atuação do designer deixou de ser linear e tecnicista e passou a entrar em universos até certo ponto desconhecidos que demandam uma decodificação em busca de qualidades intangíveis. O Design somente conseguirá ultrapassar essas barreiras se interagir de forma transversal e transdisciplinar, com disciplinas tanto objetivas e exatas como humanas, estéticas e sociais. O designer passará a assumir um papel de gestor dessa complexidade (MORAES, 2008). A complexidade, definida como o número de elementos que compõem um sistema, está intrínseca no Design, uma vez que este envolve conceitos de diversos campos do conhecimento de acordo com o objeto de projeto que está sendo manipulado, fazendo com que seja inevitavelmente uma forma de conhecimento transdisciplinar.

\section{A integração entre o Design e a Engenharia}

Uma visão integrada do processo de inovação advoga pela união da Ciência, do Design e do Empreendedorismo que, juntas poderão produzir resultados mais efetivos do que o discurso da inovação como fenômeno ou invenção. As três áreas envolvem processos criativos, incertos e caros: a Ciência refere-se à criação de conhecimento do mundo natural anteriormente desconhecido; o Design cria novos artefatos que não existiam anteriormente e o Empreendedorismo estabelece novos negócios ou usos que também não existiam antes. $O$ conhecimento existente sobre o gerenciamento de processos de Design pode ser aproveitado para entender e orientar os processos de Ciência e Empreendedorismo, uma vez que o Design não garante a obtenção de uma invenção, embora crie a possibilidade de alcançá-la; e cientistas, designers, engenheiros e empreendedores podem aprender uns com os outros melhorando seus próprios processos de desenvolvimento (LUO, 2015).

Uma mudança cultural da mentalidade orientada pela Engenharia, que considera primeiro os recursos disponíveis, para uma mentalidade orientada pelo Design, que coloca o usuário primeiro no processo, é o primeiro passo para que esta integração aconteça. Designers vão além do trabalho de Design e atuam como agentes de mudança, influenciando o ambiente, atraindo as outras pessoas para suas ideias e mudando a mentalidade da organização em geral, além de serem mais bem compreendidos e 
valorizados. Um dos principais problemas vivenciados pelos designers em organizações orientadas pela Engenharia é que geralmente são envolvidos tarde demais no processo de desenvolvimento. $O$ envolvimento precoce permite que os designers conheçam as necessidades dos usuários antes do início do desenvolvimento e trabalhem em conjunto com os demais envolvidos para que possam, assim, participar também da definição do escopo e das metas do projeto (BJÖRKLUND e KEIPI, 2019). Então, parafraseando Dym (2005), o que a palavra "Design" significa em um contexto de Engenharia?

Uma das formas da Engenharia descrever as ações e atributos relacionados ao Design é por meio do termo Engineering Design ou Design de Engenharia ou ainda, numa tradução ao pé da letra, Projeto de Engenharia (DYM, LITTLE e ORWIN, 2013).

Engineering Design é um processo sistemático e inteligente no qual os designers geram, avaliam e especificam conceitos para dispositivos, sistemas ou processos cuja forma e função atingem os objetivos dos clientes ou as necessidades dos usuários, enquanto satisfazem um conjunto especificado de restrições (DYM et al., 2005, p. 104).

Essa definição considera o projeto de Engenharia como um processo ponderado que depende da geração sistemática e inteligente de conceitos de Design e das especificações que possibilitam a realização desses conceitos num processo cognitivo complexo (DYM et al., 2005). Neste contexto, as competências que caracterizam o Design Thinking estão associadas com as habilidades de: 1) tolerar a ambiguidade do loop iterativo do pensamento divergente-convergente; 2 ) manter a visão geral do todo, incluindo o pensamento sistêmico e o Design de sistemas; 3) lidar com a incerteza; 4) tomar decisões; 5) pensar como parte de uma equipe em um processo social; e 6) pensar e se comunicar nas várias linguagens do Design.

Ao considerar o conceito de Engineering Design, assume-se que o Design emerge de um processo sistemático, inteligente e ponderado que pode ser entendido e, portanto, ensinado e aprendido e os métodos formais que usamos para gerar alternativas de Design seguem naturalmente a inclinação de pensar sobre o Design, fazendo parte do processo (formal) para identificar e esclarecer o que um cliente deseja (ou seja, os objetivos), precisa (ou seja, as restrições) e pretende que o Design faça (ou seja, suas funções) (DYM, LITTLE e ORWIN, 2013). A educação em Design representa sérios desafios e gloriosas oportunidades. Design é o que os engenheiros fazem, e o Design inteligente e "pensativo" do currículo de Engenharia deveria ser seu primeiro comprometimento (DYM et al., 2005).

o Engineering Design Thinking é um tópico de interesse para os profissionais e pesquisadores de STEM pois é um processo cognitivo complexo, que inclui o pensamento divergente-convergente, a perspectiva de sistemas, a ambiguidade e a colaboração. O Design geralmente é complexo, envolvendo vários níveis de componentes em interação em um sistema que pode ser aninhado ou conectado a outros sistemas. $O$ pensamento sistêmico é uma faceta essencial da cognição do Engineering Design (DYM et al., 2005; FACCA, BARBOSA e ALVES, 2019; LAMMI e BECKER, 2013). 


\section{Design e 0 ensino de Engenharia}

Apesar do visível crescimento de admissões nos cursos de Engenharia, o setor produtivo tem encontrado dificuldades para recrutar profissionais qualificados para atuar na fronteira do conhecimento da Engenharia, o que, além da técnica, tem demandado também que estes tenham domínio de habilidades como liderança, trabalho em equipe, planejamento, gestão estratégica e aprendizado autônomo. Tais competências, conhecidas como "soft skills", combinam sólido treinamento técnico com uma formação mais humanística e empreendedora (BRASIL, 2019). As soft skills ou "habilidades leves" são os atributos pessoais, traços de personalidade, sinais sociais inerentes e habilidades de comunicação necessárias para o sucesso no trabalho que caracterizam como uma pessoa interage em seus relacionamentos com outras pessoas. Diferentemente das "hard skills" ou "habilidades duras", que podem ser obtidas por meio da educação convencional, programas de treinamento, certificações e treinamentos no trabalho, e que são tipicamente quantificáveis e facilmente definidas e avaliadas, as habilidades leves são semelhantes às emoções ou ideias que permitem que as pessoas "leiam" umas às outras. As soft skills incluem habilidades não técnicas como empatia, adaptabilidade, atitude pró ativa, comunicação, pensamento criativo, ética, trabalho em equipe, networking, tomada de decisões, positividade, gerenciamento de tempo, motivação, flexibilidade, resolução de problemas, pensamento crítico e resolução de conflitos (THE BALANCECAREERS, 2020). Apesar do Design estar mais familiarizado com essas competências é necessário desenvolver nos designers as mesmas habilidades.

Em vista do lugar central ocupado pela Engenharia na geração de conhecimento, tecnologias e inovações, é estratégico considerar essas novas tendências e habilidades e enfatizar a melhoria da qualidade dos cursos oferecidos, a fim de aumentar a produtividade e ampliar as possibilidades econômicas hoje e num futuro próximo (BRASIL, 2019). A trilha da Engenharia é tipicamente direcionada àqueles que usarão uma combinação de conhecimentos e entendimentos, gerais e especializados, para otimizar a aplicação de tecnologia existente e emergente, utilizando métodos teóricos e práticos adequados à análise e solução de problemas por meio do Design, desenvolvimento, fabricação, comissionamento, operação e manutenção de produtos, equipamentos, processos e serviços, entre outras funções (UNESCO, 2010).

As propostas de modernização dos cursos de Engenharia devem considerar as tendências internacionais, bem como os aspectos específicos da realidade de cada país, com visões mais multidisciplinares, sistêmicas e consistentes. Todos esses aspectos devem estar alinhados às necessidades da sociedade, especialmente em relação às questões de sustentabilidade, áreas futuras (como nanotecnologia e biotecnologia) e a nova geração de produção, indústria 4.0 (abrangendo, por exemplo, automação avançada, big data, inteligência artificial, Design e circuitos integrados, etc.). Em experiências internacionais, os currículos têm focado no desenvolvimento de 
competências e na adoção de metodologias de ensino mais orientadas para a prática, como o PBL (Problem Based Learning) e o PjBL (Project Based Learning), o ensino híbrido que, baseado no uso de tecnologias digitais, utiliza simultaneamente ensino presencial e a distância, (CNI, 2018). O conhecimento de Engenharia sempre foi baseado num sistema onde se trabalha com os fenômenos das "caixas pretas" em seu Design. O novo desafio não é trabalhar com tais caixas pretas, mas desenvolver o trabalho em equipes interculturais, interdisciplinares e colaborativas (UNESCO, 2010).

Segundo Fontoura (2011), o Design, interdisciplinar por natureza, é uma área propícia para trabalhar em conjunto com outras áreas de conhecimento, como a Engenharia por exemplo, e pode atuar como agente no processo de relações entre disciplinas. Concebido no século XX, o Design tem passado por uma transformação revolucionária (NANI DA FONSECA e BARBOSA, 2020), de uma atividade comercial para uma profissão segmentada e um campo de pesquisa, integrando conhecimento, combinando teoria e prática para encontrar novos propósitos produtivos e descobrir novas relações entre signos, coisas, ações e pensamentos, não se limitando apenas a uma especialização técnica (BUCHANAN, 1992).

O Design pode alterar seu espectro de desempenho, saindo de uma condição estritamente projetual, onde era meramente responsável por atribuir função e forma aos objetos, para uma participação mais ampla, onde se torna parte de todo o processo de desenvolvimento de produtos e serviços, sendo utilizado como fator diferenciador, demonstrando sua participação na cadeia de inovação para enfrentar os efeitos da globalização. Inovação esta que pode ser considerada uma atitude para que, através do Design, possa proporcionar uma visão mais ampla das possibilidades de criação de negócios, melhoria de processos, criação de valores agregados, criação de canais de vendas, criação de marca e, fundamentalmente, contribuição para a experiência do consumidor (DDI-CBA, 2008). O Design pode ajudar, por meio de suas ferramentas e metodologias, mostrando novos caminhos inspirados não apenas em novas tecnologias, mas também nas necessidades humanas, agregando novos valores que possam ser percebidos pelos consumidores e implementados de forma viável (BROWN, 2009).

Em resposta às contínuas transformações sociais e tecnológicas, muitas organizações chamam a atenção para a necessidade de mudanças urgentes nos sistemas educacionais. Em função de sua abordagem colaborativa e criativa, de ser centrado no ser humano e de sua interdisciplinaridade, o Design thinking é visto como uma mentalidade e um método úteis para enfrentar o desafio de um novo paradigma de aprendizado (TSCHIMMEL e SANTOS, 2018) e pode representar o próximo passo, sendo aplicado numa variedade de situações e problemas por quem nunca pensou que poderia pensar ou agir como designer (BROWN, 2009). A metodologia de Design Thinking pode ser uma contribuição importante para um novo processo de 
construção de visão para sistemas educacionais e pode ajudar na exploração e organização de diversas informações; através de ferramentas de visualização, mapeamento e prototipagem e ajudando a entender e resolver problemas mal definidos (TSCHIMMEL e SANTOS, 2018).

O foco na compreensão de sistemas complexos e na solução de problemas é a chave para solucionar grandes questões e a educação, com o objetivo de aprimorar não apenas as habilidades técnicas, mas também outras dimensões humanas, incluindo o Design Thinking é da maior importância. Como consequência, o aprendizado e o ensino precisam ocorrer em um ambiente de apoio que abraça processos de pensamento divergentes e metodologias de Design, dentro de uma infraestrutura que permita troca intelectual aberta, aprendizado ativo, teoria, inovação e pesquisa (ALTRINGER e HABBAL, 2015). Reforçando essa abordagem, Ericson et al. (2009) identificam três pontos-chaves que justificam o uso da metodologia do Design Thinking na educação em Engenharia: 1) abordagens integradas não são muito implementadas, 2) o treinamento das soft skills proporciona uma mudança de pensamento e 3) a necessidade de uma competência social para usar o Design thinking. A Engenharia, por sua essência, é fundamentalmente técnica para a solução de problemas e pode facilmente hospedar essa mudança de paradigma quando se fala em inovação (FACCA, BARBOSA e ALVES, 2019).

\section{Panorama da participação do Design na graduação em Engenharia}

De acordo com a metodologia de pesquisa foi realizada uma investigação exploratória e descritiva com o objetivo de levantar dados e informações referentes ao panorama da participação do Design na graduação em Engenharia nas principais instituições de ensino superior tanto no Brasil como no mundo (FACCA, 2020). Esse levantamento foi dividido em duas etapas. Primeiramente foi feito um levantamento de como o Design está sendo inserido nos cursos de Engenharia e depois, foi pesquisado como o Design e a Engenharia estão convivendo em cursos integrados; nos dois casos estão sendo considerados os panoramas nacionais e internacionais. A seleção dos cursos e instituições pesquisados foi feita baseada em duas bases de dados, descritas a seguir.

\section{O Design inserido nos cursos de Engenharia}

Há várias formas de o Design, seja como conteúdo, como disciplina ou como curso, participar da formação do engenheiro. A inserção do Design nos cursos de graduação em Engenharia pode acontecer: 1) como disciplina 
obrigatória ${ }^{5}$ curricular; 2) como disciplina eletiva ${ }^{6}$ (ou optativa ${ }^{7}$ ) curricular; 3) como conteúdo programático abordado em uma disciplina obrigatória ou eletiva curricular; 4) como curso de extensão ou extracurricular; 5) como especialização ou minor8; e/ou 6) como conteúdo vinculado a um projeto integrado extracurricular (FACCA, BARBOSA e ALVES, 2019).

Além disso deve-se levar em conta também dois aspectos importantes para a introdução do Design para estudantes de Engenharia em nível de graduação: "quando" e "como" o tema é abordado. "Quando" significa que ele pode ser introduzido no primeiro ano, tornando o Design um tema central nos estágios iniciais do estudo, mas talvez muito cedo para ser eficaz ou eletivo, ou no último ano, como acompanhamento ou uma aplicação prática sobre o que os alunos aprenderam no primeiro ano, mas talvez tarde demais para trazer algum efeito real. "Como" é sobre o método e significa que ele pode ser ensinado não apenas com o foco principal baseado na estética, mas também na usabilidade, sustentabilidade e na fabricação (DYM et al., 2005; FACCA, BARBOSA e ALVES, 2019; SATHIKH, 2018).

\section{Panorama nacional}

No cenário nacional, para se conhecer como o Design está sendo inserido nos cursos de Engenharia nas IES brasileiras, foi consultada a base de dados do INEP-MEC e foi utilizado como parâmetro o Exame Nacional de Desempenho dos Estudantes (ENADE) de 2017, ano em que os cursos de Engenharia foram avaliados e cujo resultado foi divulgado em $2018^{\circ}$. O Conceito ENADE é um indicador de qualidade que avalia os cursos por intermédio do desempenho dos estudantes e respostas ao Questionário do Estudante (percepção dos discentes sobre as condições oferta do processo formativo). Neste caso foi consultada a área de avaliação de Engenharia que engloba os cursos de Engenharia, Engenharia da Computação, Engenharia Civil, Engenharia Elétrica, Engenharia de Controle e Automação, Engenharia Mecânica, Engenharia de Alimentos, Engenharia Química, Engenharia de Produção, Engenharia Ambiental e Engenharia Florestal (INEP/MEC, 2020). O Enade 2017 avaliou 2803 cursos de todo o Brasil, de instituições públicas e privadas, incluindo Universidades, Centros Universitários, Faculdades, Centros e Institutos Federais, nas modalidades de ensino presencial e à distância.

Para compor o universo da pesquisa no âmbito nacional foi selecionada uma amostra não aleatória composta pelos cursos que obtiveram as 100 maiores médias do Conceito Enade (contínuo) de 2017, variando de 5,0000 a 4,1716, o que equivale ao Conceito 5 (faixa).

O levantamento das informações foi realizado por meio da consulta do conteúdo online disponível nos sites de cada instituição, a página do referido curso de graduação (geralmente dentro do menu "Ensino"), os Projetos Pedagógicos de Curso (PPC) e/ou as matrizes curriculares do curso, utilizando sempre como palavra-chave de busca o termo "Design". 


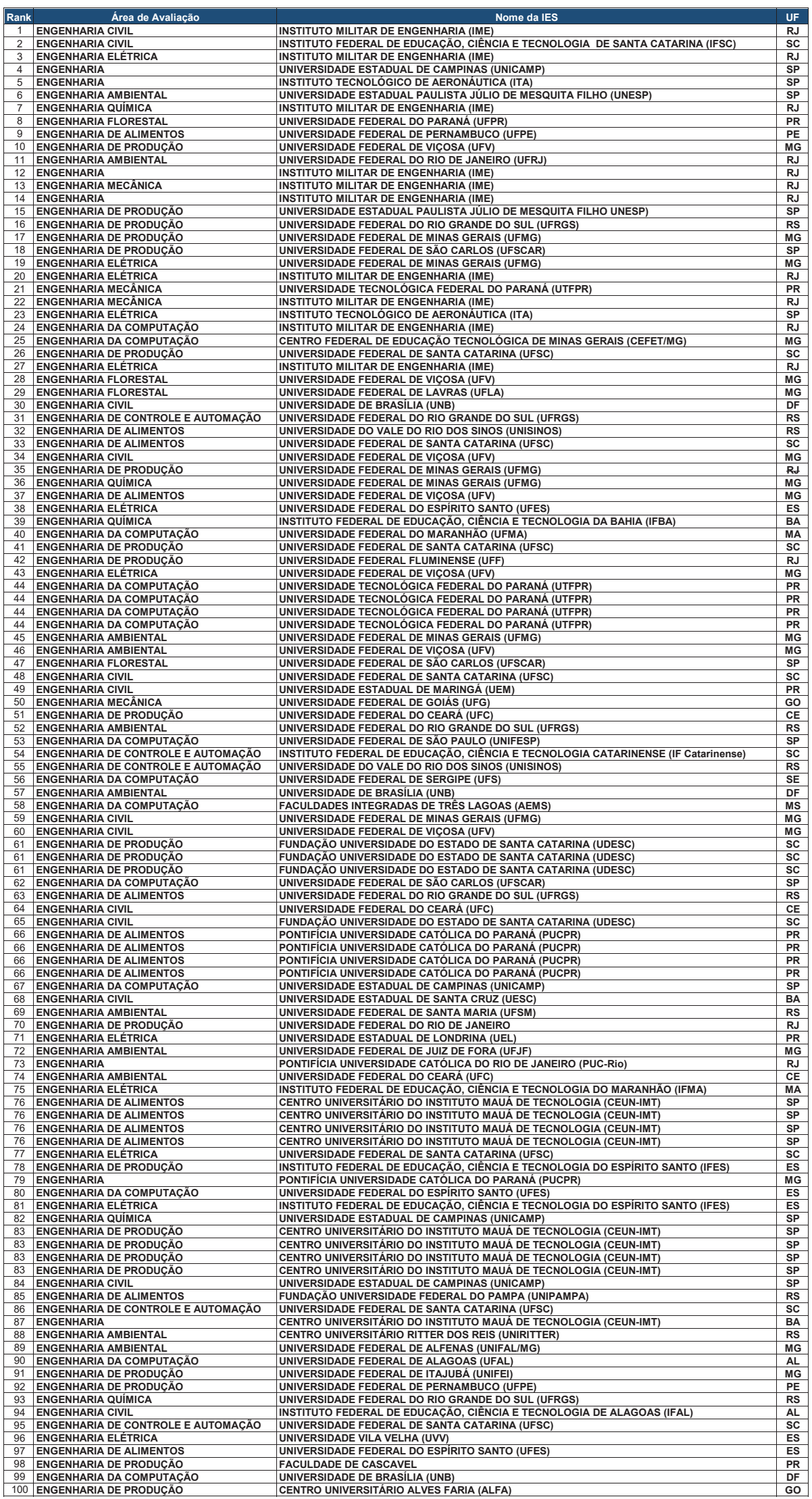

Tabela 1. Cursos e IES selecionados panorama nacional | Fonte: Dados compilados pelos autores (INEP/MEC, 2020)
99 ENGENHARIA DA COMPUTAC̄A 
Segundo os dados levantados do INEP-MEC (2020), os 100 melhores cursos de Engenharia avaliados no Brasil em 2017, de acordo com o Conceito Enade, são oferecidos por 48 IES, de 16 UF, estando a maioria delas nas regiões Sul (28\%) e Sudeste (53 \%), de acordo com o apresentado na Tabela 1.

Estas 48 IES estão distribuídas majoritariamente da seguinte forma: $100 \%$ na modalidade de ensino "presencial", 78 \% na categoria administrativa "Pública Federal", 73 \% na organização acadêmica como "Universidade", englobando 11 "áreas de avaliação" de Engenharia.

No quesito "IES que oferece alguma graduação em Design", dentre as 48 IES pesquisadas, 31 oferecem cursos de Design (65\%), 16 oferecem apenas cursos de Design no mesmo campus pesquisado (33\%), e 12 não oferecem nada relacionado ao Design ( $25 \%)$. Dentre elas, foram encontradas as seguintes habilitações: Design (27 \%), Moda (18\%), Produto (16 \%), Gráfico (14\%), Industrial (10\%), Interiores (4\%), Visual (4\%), Digital (4\%) e Ambientes (2\%).

Quanto aos quesitos "IES que oferece algum Programa Minor que possui o termo 'Design' na sua nomenclatura" e "IES que oferece alguma disciplina de Minor que possui o termo 'Design' na sua nomenclatura” apenas uma instituição foi encontrada, oferecendo o Minor de Design e Inovação para os cursos de Engenharia de Alimentos e de Produção, com duas disciplinas de Design (Design thinking e Design Estratégico e Inovação), ambas optativas, semestrais e nas últimas séries.

Quanto ao quesito "IES que oferece algum Curso ou Programa de Extensão que aborda o Design", apenas 4 IES (8 \%) oferecem alguma atividade relacionada ao Design.

Ao ser pesquisado qual "IES oferece algum Projeto que aborda o Design", a atividade que mais apareceu foi o Aero Design ( $87 \%$ do total de projetos), em $27 \%$ das instituições e $28 \%$ dos cursos. Apesar de apresentarem baixas porcentagens, surgiram projetos interessantes como Rocket Design e Projeto Mulheres em STEM2D, no Instituto Aeronáutico de Engenharia (ITA) e os Projetos e Atividades Especiais (PAE) no CEUN-IMT, que oferecem uma série de projetos eletivos na área de Design aos alunos dos cursos de Engenharia e Administração, tais como: Design de novas soluções para tecnologias vestíveis (wearable technology), CMF Design (Color Material Finish), Design de Game - Desenho de Personagens, Design Neurolab - experiências em neurociência aplicada ao Design, Universo da cor: cor, Design e marketing, Design de joias contemporâneas, Lighting Design, Design de brinquedo para o pensamento computacional, entre outros.

Quanto aos quesitos "IES que oferece alguma disciplina regular que possui o termo "Design" na sua nomenclatura" e "Curso que oferece alguma disciplina regular que possui o termo "Design" na sua nomenclatura", foram encontradas 14 disciplinas regulares, em 7 IES localizadas majoritariamente na região Sul do Brasil (71\%), representando $15 \%$ do universo total pesquisado, em 7 dos cursos avaliados (7\%), nas áreas de Engenharia de Alimentos (36 \%), En- 
genharia da Computação (29 \%), Engenharia de Produção (21 \%), Engenharia Ambiental (7 \%) e Engenharia Elétrica (7 \%). São elas: Design de Interação, Web Design, Design Instrucional, Tópicos em Design de Interação (no curso de Engenharia de Computação); Introdução ao Design, Design e Projeto de Produto I e II (no curso de Engenharia de Produção); Concepção e Design em Engenharia, Design de Processos e Plantas Industriais, Concepção e Design de Produtos Alimentícios, Concepção e Design de Projeto Transformador, Food Design (no curso de Engenharia de Alimentos); Ecodesign em Projetos Industriais (no curso de Engenharia Ambiental) e Inovação e Design thinking (no curso de Engenharia Elétrica). Das disciplinas encontradas a maioria é semestral (93\%), obrigatória (50\%) ou eletiva (43\%) e está sendo oferecida nos 4 últimos períodos (79\%).

Ao pesquisar se alguma "IES ou Curso de Engenharia oferece o "Design" como conteúdo programático de outras disciplinas curriculares" foram encontradas 8 IES (17 \%) e 9 cursos de Engenharia (9\%) dentro deste escopo, todas na Região Sudeste (SP, MG e ES). Dentre os principais conteúdos abordados estão: Ecodesign, Design thinking, Design de Interação e Ferramentas de Design para a Engenharia (DFX, DFM, DFA, DFD, DFSS).

Quanto ao quesito "IES que oferece algum curso integrado entre Design $e$ Engenharia", dentre as IES pesquisadas não foi encontrado nenhum caso específico em que os termos "Design" e "Engenharia" estão contidos na nomenclatura de algum curso de graduação.

Esta pesquisa, apesar de poder ter algumas limitações, foi uma tentativa de verificar o estado da arte do ensino do Design nos cursos superiores de Engenharia no Brasil, tendo em conta as tendências mundiais atuais de interdisciplinaridade. No cenário nacional, apesar de as IES pesquisadas oferecerem em sua maioria cursos de graduação em Design, a porcentagem de IES que insere o Design em seus cursos de Engenharia, seja como conteúdo ou como disciplina regular ainda é muito pequena, e inexistente quando se trata de um curso criado de forma integrada das duas áreas. Essa constatação pode abrir um grande espaço de crescimento e uma oportunidade de incorporação do Design como um elemento novo e diferenciado na formação dos engenheiros, o que se demonstra alinhado às tendências analisadas de educação e inovação, mas que ainda aparece timidamente no contexto acadêmico da Engenharia no Brasil. 


\section{Panorama internacional}

No cenário internacional, para conhecermos como o Design está sendo inserido nos cursos de Engenharia nas melhores IES do mundo foi utilizado um critério diferente do utilizado no panorama nacional, uma vez que os rankings utilizam metodologias diferentes de avaliação e os dados disponíveis não apresentam as mesmas varáveis do cenário nacional. Foi adotado, então, um critério inicialmente de ordem geográfica, selecionando as melhores IES nas áreas de Engenharia nos países considerados como referência global de acordo com os principais rankings de inovação, tecnologia e educação divulgados em 2019 e 2020 (ARWU, 2019; GII, 2019; QS, 2020; THE, 2019; U.S. NEWS, 2020). Uma vez selecionados os países e as IES, o critério de seleção dos cursos oferecidos pelas IES foi baseado no método de amostragem aleatória, onde cada elemento do universo pesquisado tem a mesma chance de ser escolhido para compor a amostra (LEVIN e FOX, 2004). Assim foi escolhido um curso diferente em cada IES a fim de cobrir uma grande variedade de áreas, incluindo as mesmas áreas de avaliação da pesquisa no cenário nacional.

Foi consultado o conteúdo online disponível nos sites de cada instituição, a página do referido curso de graduação (geralmente dentro do menu "academics"), os programas e/ou as matrizes curriculares do curso, utilizando sempre como palavra-chave de busca o termo "Design", ou se fosse o caso, o termo correspondente na língua do site como "Diseño", em espanhol ou "Entwurf", em alemão.

Segundo os dados levantados no contexto internacional (ARWU, 2019; THE, 2019; U.S. NEWS, 2020; QS, 2020), foram avaliados 22 cursos de 22 IES, em 16 países na América, Europa e Ásia (Tabela 2).

Estas IES estão distribuídas majoritariamente da seguinte forma: $100 \%$ na modalidade de ensino "presencial", 77 \% na categoria administrativa "Pública", 73 \% na organização acadêmica como "Universidade", englobando cursos de Bacharelado (BSc), Licenciatura ou Mestrado integrado" (MEng) em 15 "áreas de avaliação" de Engenharia: Bioengenharia, Ciência da Engenharia, Engenharia Aeroespacial, Engenharia Ambiental, Engenharia Civil, Engenharia de Alimentos, Engenharia de Automação, Engenharia de Computação, Engenharia de Produção e Gestão Industrial, Engenharia e Ciências de Materiais, Engenharia Elétrica, Engenharia Eletrônica, Engenharia Mecânica, Engenharia Química, Sistemas e Design de Engenharia. 
um panorama nacional e internacional

\begin{tabular}{|c|c|c|}
\hline País & IES & Área de Avaliação \\
\hline Alemanha & Technical University of Munich (TUM) & Mechanical Engineering \\
\hline Brasil & Universidade de São Paulo (USP) & Engenharia de Produção \\
\hline Canadá & University of Toronto (UT) & Engineering Science \\
\hline Chile & Pontifical Catholic University of Chile (PUC-Chile) & Ciencias de la Ingeniería \\
\hline China & Peking University (PU) & Electronic Engineering \\
\hline Coreia do Sul & $\begin{array}{l}\text { Korea Advanced Institute of Sci- } \\
\text { ence \& Technology (KAIST) }\end{array}$ & Materials Science and Engineering \\
\hline \multirow[t]{4}{*}{ Estados Unidos } & California Institute of Technology (Caltech) & Civil Engineering \\
\hline & Harvard University (HU) & Bioengineering \\
\hline & Massachusetts Institute of Technology (MIT) & Electrical Engineering and Computer Science \\
\hline & Stanford University (SU) & Environmental Systems Engineering \\
\hline Finlândia & Aalto University (AU) & Computational Engineering \\
\hline Holanda & Delft University of Technology (DUT) & Computer Science and Engineering \\
\hline Itália & Politecnico di Milano (Polimi) & Automation Engineering \\
\hline Japão & The University of Tokyo (UOT) & Chemical System Engineering \\
\hline México & $\begin{array}{l}\text { Universidad Nacional Autóno- } \\
\text { ma de México (UNAM) }\end{array}$ & Ingeniería en Alimentos \\
\hline \multirow[t]{2}{*}{ Portugal } & Instituto Politécnico do Porto (IPP) & Engenharia e Gestão Industrial \\
\hline & Universidade do Porto (UP) & Engenharia Mecânica \\
\hline \multirow[t]{2}{*}{ Reino Unido } & University of Cambridge (UC) & Mechanical Engineering \\
\hline & University of Oxford (U0) & Engineering Science \\
\hline \multirow[t]{2}{*}{ Singapura } & Nanyang Technological University (NTU) & Aerospace Engineering \\
\hline & $\begin{array}{l}\text { Singapore University of Technol- } \\
\text { ogy and Design (SUTD) }\end{array}$ & Engineering Systems and Design \\
\hline Suíça & $\begin{array}{l}\text { ETH Zurich - Swiss Federal In- } \\
\text { stitute of Technology }\end{array}$ & $\begin{array}{l}\text { Electrical Engineering and In- } \\
\text { formation Technology }\end{array}$ \\
\hline
\end{tabular}

Tabela 2. Cursos e IES selecionados - panorama nacional

Fonte: Os autores, 2020

No quesito "IES que oferece alguma graduação em Design", dentre as 22 IES pesquisadas, 10 oferecem cursos de Design (45\%) e todas (100\%) oferecem alguma variável pesquisada relacionada ao Design (disciplina, conteúdo, projeto, curso, minor etc.). Dentre as graduações em Design, foram encontradas as seguintes habilitações: Design; Design Arquitetônico; Design de Comunicação; Design de Moda; Design de Interiores; Arte, Design e Mídia; Arte e Design; Design Gráfico; Design Industrial; Design Gráfico e Publicidade; Design de Produto; Sistemas e Design Digitais. 
Nota-se que a Universidade de São Paulo (USP) foi considerada no panorama internacional pois é a única IES brasileira que aparece nos rankings pesquisados.

Ao ser pesquisado qual "IES oferece algum Projeto que aborda o Design", surgiram atividades em 5 IES (23\%), em 4 países, em segmentos variados.

Quanto ao quesito "IES que oferece algum Curso ou Formação complementar que aborda o Design", os resultados mostraram que 10 IES (45\%) oferecem algum tipo de curso ou formação complementar relacionada ao Design.

Ao pesquisar se alguma "IES ou Curso de Engenharia oferece o 'Design' como conteúdo programático de outras disciplinas curriculares" foram encontradas 6 IES (27 \%) que se encaixam nesse padrão.

Quanto ao quesito "IES/Curso que oferece alguma disciplina regular que possui o termo 'Design' na sua nomenclatura”, foram encontradas 18 IES (82\%) que oferecem disciplinas curriculares relacionadas ao Design.

No cenário internacional, a porcentagem de IES que insere o Design de alguma forma em seus cursos de Engenharia é total (100\%).

$\mathrm{Na}$ Tabela 3 é possível verificar os resultados comparativos entre os panoramas nacional e internacional, referentes aos dados levantados. É interessante observar que no Brasil a porcentagem de IES que oferece o curso de graduação em Design ( $65 \%$ ), além dos cursos de Engenharia, é maior do que nas IES no cenário internacional (45\%). Entretanto, ao analisar os resultados referentes às demais variáveis pesquisadas que inserem o Design de alguma forma nos cursos de Engenharia, seja como disciplina, conteúdo, projeto ou curso, percebe-se que os valores encontrados são maiores do que no Brasil (com exceção da variável de projetos), principalmente em relação à oferta de alguma disciplina regular que possui o termo "Design" na sua nomenclatura ( $82 \%)$. E quanto à oferta de algum curso integrado de Design e Engenharia (o que será abordado no próximo capítulo) é lamentável perceber que no Brasil a situação é inexistente enquanto nas IES pesquisadas $36 \%$ atende a esse quesito. E o mais surpreendente foi a comprovação de que $100 \%$ das IES pesquisadas oferece algum tipo de inserção do Design na formação do Engenheiro, não importando o perfil da IES, sua localização geográfica ou a área de avaliação. Esse resultado indica que o Design já faz parte da formação do Engenheiro no panorama internacional, demonstrando um alinhamento em relação ao que está sendo mostrado pelas tendências futuras de educação e inovação em todo o mundo. 


\begin{tabular}{l|l|l}
\hline Variável Pesquisada & $\begin{array}{l}\text { Resultado } \\
\text { Nacional }\end{array}$ & $\begin{array}{l}\text { Resultado } \\
\text { Internacional }\end{array}$ \\
\hline $\begin{array}{l}\text { IES que insere o Design de alguma forma no curso de } \\
\text { Engenharia (disciplina, conteúdo, projeto, curso) }\end{array}$ & $67 \%$ & $100 \%$ \\
\hline IES que oferece alguma Graduação em Design & $65 \%$ & $45 \%$ \\
\hline IES que oferece algum Projeto que aborda o Design & $27 \%$ & $23 \%$ \\
\hline $\begin{array}{l}\text { IES que oferece algum Curso ou Formação com- } \\
\text { plementar que aborda o Design }\end{array}$ & $8 \%$ & $45 \%$ \\
\hline $\begin{array}{l}\text { IES/Curso que oferece alguma Disciplina regular que } \\
\text { possui o termo "Design" na sua nomenclatura }\end{array}$ & $15 \% / 7 \%$ & $82 \%$ \\
\hline $\begin{array}{l}\text { IES/Curso que oferece o Design como Conteúdo pro- } \\
\text { gramático de outras disciplinas curriculares }\end{array}$ & $17 \% / 9 \%$ & $27 \%$ \\
\hline \begin{tabular}{l} 
IES que oferece algum curso integrado entre Design e Engenharia \\
\hline
\end{tabular} & $0 \%$ & $36 \%$ \\
\hline
\end{tabular}

Tabela 3. Resultados comparativos entre os panoramas nacional e internacional Fonte: Dados compilados pelos autores, 2020

\section{Design e a Engenharia em cursos integrados}

$\mathrm{Na}$ pesquisa realizada entre as IES brasileiras fica bem visível a divisão entre as áreas de Design e Engenharia. Há cursos de Design e cursos de Engenharia, há disciplinas e conteúdo de Design inseridos nos cursos e disciplinas de Engenharia (e vice-versa), porém não foi encontrada uma situação (curso ou disciplina) em que as duas áreas já nascem juntas e integradas, ou seja, que contenha os dois termos simultaneamente na sua nomenclatura.

Por outro lado, na pesquisa realizada entre as IES no panorama internacional, em relação ao quesito "IES que oferece algum curso integrado entre Design e Engenharia”, foram encontrados vários casos em que as palavras "Design" e "Engineering" aparecem juntas, em 8 IES, o que equivale a $36 \%$ do total pesquisado (Tabela 4).

E analisando os casos encontrados é possível observar duas expressões particularmente que chamam a atenção: "Design Engineering" (3 casos) e "Engineering Design" (6 casos). Esses dois termos, embora semelhantes e que parecem ter o mesmo significado, trazem dois conceitos diferentes, e muitas vezes confusos, de relações entre o Design e a Engenharia. Se for feita uma tradução direta, pode-se dizer que: "Design Engineering" significa "Engenharia de Design" ou "Engenharia de Projeto" e "Engineering Design" significa "Design de Engenharia" ou "Projeto de Engenharia". 
"Engenharia de Design" e "Design de Engenharia" são expressões frequentemente usadas de forma intercambiável, mas que na verdade possuem significados diferentes. Entretanto, ambas devem ser usadas onde o desenvolvimento de um produto faz parte de um sistema técnico (EDER e HOSNEDL, 2008).

\begin{tabular}{l|l}
\hline Curso & IES \\
\hline Design Engineering (Mestrado) & Harvard University (HU) \\
\hline Engineering Design Projects (curso) & Harvard University (HU) \\
\hline $\begin{array}{l}\text { Engineering Problem Solving and Design } \\
\text { Project (curso) }\end{array}$ & Harvard University (HU) \\
\hline Industrial Design Engineering (curso) & Delft University of Technology (DUT) \\
\hline \begin{tabular}{l} 
Product Design Engineering (conteúdo) \\
\hline $\begin{array}{l}\text { Engineering Innovation and Design } \\
\text { (disciplina) }\end{array}$
\end{tabular} & Nanyang Technological University (NTU) \\
\hline $\begin{array}{l}\text { Engineering Design (disciplina) } \\
\text { Biomedical Systems Engineering Design } \\
\text { (curso) }\end{array}$ & University of Toronto (UT) \\
\hline $\begin{array}{l}\text { Senior Civil and Environmental Engineering } \\
\text { Design (curso) }\end{array}$ & Massachusetts Institute of Technology (MIT) \\
\hline $\begin{array}{l}\text { Environmental Engineering Design } \\
\text { (disciplina) }\end{array}$ & Stanford University (SU) \\
\hline $\begin{array}{l}\text { Cambridge National in Engineering Design } \\
\text { (certificado) }\end{array}$ & University of Cambridge (UC) \\
\hline $\begin{array}{l}\text { Major en Ingeniería, Diseño e Innovación } \\
\text { (graduação) }\end{array}$ & Pontifical Catholic University of Chile (PUC-Chile) \\
\hline
\end{tabular}

Tabela 4. Casos em que as palavras "Design" e "Engineering" aparecem juntas - panorama internacional | Fonte: Dados compilados pelos autores (DUT, 2020; HU, 2020; MIT, 2020; NTU, 2020; PUC-CHILE, 2020; SU, 2020; UT, 2020a)

A Engenharia de Design é uma atividade complexa, uma progressão complexa no desenvolvimento de uma "melhor" solução para um determinado problema. É um processo criativo, mas contém aspectos processuais e de rotina. Deve ser metódica e sistemática, incluir o pensamento criativo, esclarecer o pensamento, desenvolver o pensamento crítico e muitas outras formas de pensamentos, e deve usar as informações existentes, incluindo, mas não se restringindo, ao conhecimento científico (EDER e HOSNEDL, 2008, p. 5). 
O Design de Engenharia é o processo de conceber um sistema, componente ou processo para atender às necessidades, especificações, códigos e padrões desejados, dentro de restrições como saúde e segurança, custo, ética, política, sustentabilidade, construtibilidade e manufatura. É um processo iterativo, criativo e de tomada de decisão, no qual as ciências básicas, a matemática e as ciências da Engenharia são aplicadas para converter recursos de maneira ideal em soluções (ABET, 2015, p. 27)

Segundo a ABET (2015) um Design de Engenharia deve incluir a maioria dos seguintes recursos: desenvolvimento da criatividade, uso de problemas abertos, desenvolvimento e uso da teoria e metodologia modernas de Design, formulação de declarações e especificações de problemas de Design, processos de produção, Engenharia simultânea e descrição detalhada do sistema; além de incluir uma variedade de restrições realistas essenciais como fatores econômicos, segurança, confiabilidade, estética, ética e impacto social (HAIK e SHAHIN, 2011).

O Design de Engenharia é um processo sistemático e inteligente no qual os designers geram, avaliam e especificam conceitos para dispositivos, sistemas ou processos cuja forma e função atendem aos objetivos dos clientes ou às necessidades dos usuários, enquanto satisfazem um conjunto especificado de restrições (DYM et al., 2005, p. 104).

A definição de Dym (2005) coloca o Design de Engenharia como um processo que depende da geração sistemática e inteligente de conceitos de Design e das especificações que possibilitam a realização desses conceitos. Cross (2005, p. xi) ainda complementa essas definições dizendo que "o novo conceito de 'Engenharia de Design Industrial' é um conceito de 'Design de produto' que combina os dois campos mais tradicionais: o Design de Engenharia e o Design industrial"

No contexto em que esta pesquisa está sendo desenvolvida pode-se interpretar, então, que a "Engenharia de Design" equivale a uma área de atuação da Engenharia e o "Design de Engenharia" pode ser considerado como o processo de desenvolvimento de um projeto relacionado à Engenharia.

Durante toda a pesquisa do Doutorado, incluindo as visitas e experiências durante o período "sanduíche" em Portugal, alguns programas educacionais especificamente chamaram a atenção principalmente em relação a forma como a relação e a integração entre o Design e a Engenharia acontecem.

Após a pesquisa realizada sobre os panoramas nacional e internacional, conforme já foi apresentado e descrito no capítulo anterior, foi realizada, então, uma nova pesquisa exploratória na internet (por meio do buscador Google), apenas utilizando os termos "Design Engineering Course", com o objetivo de buscar cursos oferecidos pelas IES em todo o mundo, que possuem essa combinação de palavras em sua nomenclatura. 
Assim exposto, é possível observar nos resultados encontrados num panorama internacional, a existência de 24 cursos ( 23 presenciais e 1 online), em 11 países (Brasil, Canadá, Chile, Espanha, Estados Unidos, Finlândia, Holanda, Itália, Portugal, Reino Unido e Singapura), nas modalidades de Bacharelado (BSc, BEng) e Mestrado (MSc, MEng) que integram de maneira efetiva o Design e a Engenharia. Dentre estes, 13 são cursos de "Engineering Design" e 2 são de "Design Engineering". Os demais possuem os termos "Design" e "Engineering" no nome ou possuem nomes diferentes, mas com conteúdos relacionados. $\mathrm{E}$ um fato que chamou a atenção foi o Reino Unido sediar 7 deles.

Enfim, o curso de "Design Engineering", que representa 59 \% do último grupo pesquisado, pode ser interpretado, então, como uma área de formação em Engenharia, com uma abordagem em Design e projetos.

$\mathrm{Na}$ análise dos resultados encontrados é interessante destacar que os cursos pesquisados no contexto internacional combinam, em sua maioria, conteúdos de Design, Engenharia, tecnologia e negócios, misturando disciplinas específicas de cada área, em contextos multi e interdisciplinares, aplicando o que cada área tem de melhor, em prol de objetivos comuns: criar produtos inovadores, passando por todas as fases de desenvolvimento, colocando o usuário no centro do processo, preocupando-se com todas as questões relevantes (e não apenas as técnicas) e tendo uma visão sistêmica e global do projeto.

\section{Considerações Finais}

A relação entre o Design e a Engenharia possui uma história de longa data; disciplinas de Engenharia já fazem parte do currículo dos cursos de Design desde sua concepção. Porém a participação do Design, como disciplina, nos cursos de Engenharia ainda é um assunto relativamente novo e pode ser vista como uma forma de mudança de paradigma, de busca pela evolução principalmente do ponto de vista educacional. Afinal, cada vez mais é necessária a formação de um profissional com visão multidisciplinar que saiba enfrentar os desafios da tecnologia e da inovação.

A pesquisa sobre a inserção do Design nos cursos de Engenharia no Brasil e no mundo teve uma função importante para a visualização da situação atual da educação em Engenharia. Comparar os dois cenários, nacional e internacional, foi fundamental para percebermos a lacuna existente e o quanto o Brasil tem de oportunidade e espaço para crescer. A integração do Design nos cursos de Engenharia pode ser considerada como uma nova ferramenta e um elemento de diferenciação na formação dos engenheiros, principalmente na busca de uma formação mais holística e baseada nas novas competências requeridas pela sociedade. Essa constatação está alinhada às tendências observadas de educação e inovação no âmbito global, mas que ainda aparecem timidamente no contexto acadêmico da Engenharia no Brasil. 
Face às tendências atuais de ensino-aprendizagem na educação superior e, particularmente, nos cursos de graduação em Engenharia e, tendo em conta os panoramas observados nestas pesquisas, recomendam-se algumas ações: incentivar a inserção do Design nos cursos de Engenharia existentes por meio da criação de disciplinas eletivas, projetos integrados, Minors, etc. a fim de promover a real integração entre as áreas; criar programas públicos ou privados que estimulem o desenvolvimento de projetos e a participação de equipes multidisciplinares; propor novos cursos de graduação e pós graduação que integrem o Design e a Engenharia desde o início dos programas, enfim, criar iniciativas que demonstrem a importância da multi, inter e transdisciplinaridade.

\section{Agradecimentos}

O presente trabalho foi realizado com apoio da Coordenação de Aperfeiçoamento de Pessoal de Nível Superior - Brasil (CAPES) - Código de Financiamento 001.

1 Que ultrapassa os limites das fronteiras de um país (PRIBERAM, 2008-2013).

2 Que ultrapassa os limites de uma organização (PRIBERAM, 2008-2013).

3 IDEO é uma empresa de Design global norte-americana comprometida em criar impacto positivo por meio do Design (IDEO, 2020).

4 "A expressão "caixa preta" é usada em Cibernética sempre que uma máquina ou um conjunto de comandos se revela complexo demais. Em seu lugar, é desenhada uma caixinha preta, a respeito da qual não é preciso saber nada, senão o que nela entra e o que dela sai" (LATOUR, 2000, p. 14). 5 As disciplinas obrigatórias compõem a matriz curricular básica do curso e são necessárias para que os estudantes concluam sua formação, (E+B, 2019).

6 As disciplinas eletivas são aquelas que 0 aluno pode escolher qual cursar, porém existe um número mínimo de créditos ou carga horária a ser cumprida (E+B, 2019).

7 As disciplinas optativas são disponibilizadas pelas instituições como uma forma de ampliar a formação do estudante. Nesse caso, o aluno pode escolher qual disciplina cursar, mas não é obrigado a cumpri-las. Com as optativas o estudante tem a possibilidade de moldar a sua capacitação conforme os seus objetivos profissionais (E+B, 2019).

8 Um programa minor permite ao estudante cursar um conjunto coerente de disciplinas eletivas, gerando especialização em nível de graduação e complementando sua formação principal (IMT, 2020).

9 Os cursos de Engenharia foram avaliados novamente em 2019, porém os resultados até o presente momento ainda não foram divulgados.

100 Mestrado Integrado refere-se ao curso de 5 anos, considerando 3 anos de formação básica (Major) e 2 anos de formação específica (Minor). 


\section{Referências}

ABET. 1985 Annual Report. ABET - Accreditation Board for Engineering and Technology. New York. 1986.

ABET. Criteria for Accrediting Engineering Programs, 2016 - 2017. ABET - Accreditation Board for Engineering and Technology, Inc.. Baltimore, MD, p. 31. 2015.

ALTRINGER, B.; HABBAL, F. Embedding Design Thinking in a Multidisciplinary Engineering Curriculum. Open, 2015. Disponível em: https://e-channel.med.utah.edu/wp-content/uploads/2016/02/venturewell2015_paper_ALTRINGER.pdf. Acesso em: 11 jan. 2020.

ARWU. ARWU - Shanghai Ranking's Academic Ranking of World Universities 2019. ARWU Shanghai Ranking's Academic Ranking of World Universities 2019, 2019. Disponível em: http://www.shanghairanking.com/index.html. Acesso em: 15 jan. 2020.

BERTOLA, P.; MANZINI, E. Design Multiverso: appunti di fenomenologia del design. Milano: POLIDesign, 2004. 10-17 p.

BJÖRKLUND, T.; KEIPI, T. (. ). Design +: Organizational renewal and innovation through design. e-book. ed. Helsinki: Aalto University - Aalto Design Factory, 2019. 222 p. ISBN 978-952-60-3783-7. Disponível em: https://aaltodoc.aalto.fi/handle/123456789/41115. Acesso em: 09 jan. 2020.

BOMFIM, G. A. Fundamentos de uma teoria transdisciplinar do design: morfologia dos objetos de uso e sistemas de comunicação. In: COUTO, R. M. D. S. et al. Gustavo Amarante Bomfim: Uma Coletânea. Rio de Janeiro, RJ: Rio Books, 2014. Cap. 4, p. 35-50.

BRASIL. Consulta acerca da inclusão do Empreendedorismo como disciplina no currículo do Ensino Fundamental, do Ensino Médio, da Educação Profissional e da Educação Superior. Ministério da Educação, Conselho Nacional de Educação. Brasília, DF, p. 8. 2010. BRASIL. Diretrizes Curriculares Nacionais do Curso de Graduação em Engenharia. Ministério da Educação. Conselho Nacional de Educação. Câmara de Educação Superior. Brasília. 2019. BRAUTIGAM, B. How Design Thinking will fix Design Thinking. Medium Muzli, 03 april 2017. Disponível em: https://medium.muz.li/how-design-thinking-will-fix-design-thinking-5ce735b4c029. Acesso em: 10 jan. 2020.

BROWN, T. Change by design. How Design Thinking transforms organizations and inspires innovation. Adobe Digital Edition. ed. New York, NY: HarperCollins ebooks, 2009. 164 p. ISBN 978-0-06-193774-3.

BUCHANAN, R. Wicked Problems in Design Thinking. Design Issues, 8, n. n.2, Spring 1992. 5-21. Disponível em: http://www.jstor.org/stable/1511637. Acesso em: 12 outubro 2019.

CNI. Ensino de engenharia : fortalecimento e modernização. Confederação Nacional da Indústria (CNI). Brasília, p. 32. 2018. (ISBN 978-85-7957-197-8).

CROSS, N. Engineering Design Methods: Strategies for Product Design. 3ª ed. Chichester: John Wiley \& Sons, Ltd, 2005.

D.SCHOOL. Design Thinking Bootleg. d.school - Stanford Design School, 2020. Disponível em: https://dschool.stanford.edu/resources/design-thinking-bootleg. Acesso em: 10 jan. 2020.

DDI-CBA. Diseño, Vision, Innovación. Ciclo de Exposiciones “Valores del Diseño". ed. Madrid: DDI-CBA (Circulo de Bellas Artes de Madrid), 2008. 127 p. ISBN 978-84-87619-37-3. Disponível em: https://www.circulobellasartes.com/wp-content/uploads/2016/04/69.pdf. Acesso em: 11 jan. 2020.

DUT. Bachelor of Computer Science and Engineering. DUT - Delft University of Technology, 2020. Disponível em: https://www.tudelft.nl/en/education/programmes/bachelors/ cse/bachelor-of-computer-science-and-engineering/. Acesso em: 19 jan. 2020. 
DYM, C. L.; AGOGINO, A. M.; ERIS, O.; FREY, D. D.; LEIFER, L. J. Engineering Design Thinking, Teaching, and Learning. Journal of Engineering Education, 94, n. №1, 2005. 104-120. Disponível em: https://onlinelibrary.wiley.com/doi/abs/10.1002/j.2168-9830.2005.tb00832.x. Acesso em: 09 novembro 2019.

DYM, C. L.; LITTLE, P.; ORWIN, E. J. Engineering Design: a project-based introduction. 4. ed. New York: Willey, 2013. 338 p. ISBN 978-1-118-32458-5.

EDER, W. E.; HOSNEDL, S. Design Engineering: A Manual for Enhanced Creativity. Boca Raton, FL: CRC Press - Taylor \& Francis Group, 2008.

ERICSON, A.; BERGSTRÖM, M.; LARSSON, A. C.; TÖRLIND, P. Design Thinking Challenges in Education. In: International Conference on Engineering Design - ICED'09. Stanford: Stanford University. 2009. p. 89-100.

ERTAS, A. Integrating Transdisciplinarity in Undergraduate Education. Transdisciplinary Journal of Engineering \& Science, 3, dez. 2012. 128-144. Disponível em: http://atlas-tjes. org/index.php/tjes/article/download/37/34. Acesso em: 27 dez. 2019.

ERTAS, A. Transdisciplinary engineering design process. Hoboken, NJ: JohnWiley \& Sons, 2018. 822 p. ISBN 9781119474777 (pdf).

ERTAS, A.; GATCHEL, S.; RAINEY, V.; TANIK, M. M. Networked Approach to Transdisciplinary Research \& Education. The Academy of Transdisciplinary Learning \& Advanced Studies, v. TAM-Vol.3, p. 1-12, 2007. ISSN 1933-5423. Disponível em: http://www.theatlas.org/index. php/about-atlas-3/honoring-dr-john-warfield-3?download=11:a-networked-approach-to-transdisciplinary-research-education. Acesso em: 09 novembro 2019.

FACCA, C. A. O Designer como Pesquisador: Uma abordagem metodológica da pesquisa aplicada ao Design de Produtos. São Paulo: Blucher Acadêmico, 2011. 190 p.

FACCA, C. A. A contribuição do pensamento do Design na formação do engenheiro: o espaço do Fab Lab como experiência transversal [tese]. Universidade Anhembi Morumbi. São Paulo, p. 254. 2020. Orientadora: Prof $^{\mathrm{a}} \mathrm{Dr}^{\mathrm{a}}$ Ana Mae Barbosa.

FACCA, C. A.; ALVES, J. L.; BARBOSA, A. M. Overview of Design Teaching on Engineering Courses: A Comparative Study between Brazil and Portugal. In: International Conference on Education and New Developments. Porto: [s.n.]. 2019a. p. 129-133.

FACCA, C. A.; BARBOSA, A. M.; ALVES, J. L. Design Teaching in Engineering: A Transdisciplinary Aproach. In: Proceedings of the 6th Design Doctoral Conference |DDC'19: Transgression. Lisboa, Portugal: IADE - Universidade Europeia. 2019. p. 99-106.

FIGUEIREDO, A. D. D. Toward an Epistemology of Engineering. In: Workshop on Philosophy and Engineering, The Royal Academy of Engineering. London: [s.n.]. nov. 2008. p. 94-95. FONTOURA, A. M. A interdisciplinaridade e o ensino do design. Projética - Revista Científica de Design, Londrina, PR, v. 2, n. N. 2, p. 86-95, Dezembro 2011. ISSN 2236-2207. Disponível em: http:// www.uel.br/revistas/uel/index.php/projetica/article/view/8855. Acesso em: 18 outubro 2019. GII. Global Innovation Index (GII) 2019. Global Innovation Index (GII) 2019, 2019. Disponível em: https://www.globalinnovationindex.org/home. Acesso em: 16 jan. 2020.

GRAHAM, D. R. The global state of the art in engineering education. Massachusetts Institute of Technology (MIT). Cambridge, MA, p. 170. 2018. (ISBN 13: 9780692089200).

HAIK, Y.; SHAHIN, T. M. Engineering Design Process. 2a ed. Stanford, CT: Cencage Learning, 2011. HU. Course Listing. HU - Harvard University - School of Engineering and Applied Sciences, 2020. Disponível em: https://www.seas.harvard.edu/bioengineering/courses. Acesso em: 19 jan. 2020. 
IDEO. Design Thinking. IDEO Design Thinking, 2020. Disponível em: https://designthinking. ideo.com/. Acesso em: 09 jan. 2020.

INEP/MEC. Sinopse Estatística da Educação Superior 2018. INEP - Instituto Nacional de Estudos e Pesquisas Educacionais Anísio Teixeira / MEC - Ministério da Educação. Brasília. 2019. INEP/MEC. Resultados dos Indicadores de Qualidade da Educação Superior 2017. INEP - Instituto Nacional de Estudos e Pesquisas Educacionais Anísio Teixeira / MEC - Ministério da Educação. Brasília. 2020.

LAMMI, M.; BECKER, K. Engineering Design Thinking. Journal of Technology Education, 24, n. №2, Spring 2013. 55-77. Disponível em: https://scholar.lib.vt.edu/ejournals/JTE/ v24n2/pdf/lammi.pdf. Acesso em: 11 jan. 2020.

LEVIN, J.; FOX, J. A. Estatística para Ciências Humanas. Tradução de Alfredo Alves Farias. 9ª ed. São Paulo: Pearson - Prentice Hall, 2004.

LUO, J. The united innovation process: integrating science, design, and entrepreneurship as sub-processes. Design Science, 1, n. №2, 2015. Disponível em: journals.cambridge.org/dsj. Acesso em: 10 jan. 2020.

MAGALHÃES, A. B. D. A evolução dos modelos educativos e a formação de engenheiros-cidadãos para o mundo. Porto, Portugal: Publindústria, 2014.

MICHELI, P.; WILNER, S. J.; BHATTI, S. H.; M.MURA; BEVERLAND, M. B. Doind design Thinking: Conceptual review, synthesis and research agenda. Journal of Product Innovation Management, august 2018. 124-148. Disponível em: https://www.researchgate.net/ publication/327054702_Doing_Design_Thinking_Conceptual_Review_Synthesis_and_Research_Agenda/link/5b992bce4585153105826d65/download. Acesso em: 09 jan. 2020.

MIT. Undergraduate Programs. MIT - Massachusetts Institute of Technology - EECS Electrical Engineering \& Computer Science, 2020. Disponível em: https://www.eecs.mit. edu/academics-admissions/undergraduate-programs. Acesso em: 19 jan. 2020.

MORAES, D. D. Design e Complexidade. Cadernos de Estudos Avançados em Design: Transversalidade, Belo Horizonte, MG, 1, n. Caderno 2, julho 2008. 7-21. Disponível em: https://www.researchgate.net/publication/215640381_Design_e_transversalidade. Acesso em: 03 novembro 2019.

NANI DA FONSECA, A.; BARBOSA, A. M. Colonização e Ensino do Design. DATJournal Design, Art and Technology, São Paulo, 5, n. 1, 2020. 220-243. Disponível em: https://datjournal. anhembi.br/dat/article/view/181. Acesso em: 17 maio 2020.

NESTERIUK, S.; INGS, W. Novos Pensamentos \& Reflexões Emergentes: Prática enquanto pesquisa em arte, design e tecnologia. DATJournal Design Art and Technology, São Paulo, 3, n. 2, 2018. 3-8. Disponível em: https://datjournal.anhembi.br/dat/issue/view/7. Acesso em: 17 maio 2020. NITZ, M.; LEONI, R. R. Evolução da Oferta, Demanda e Evasão de Cursos de Engenharia no Brasil entre 2013 e 2017: Uma análise com base nos microdados do INEP. In: Anais COBENGE 2019 - XLVII Congresso Brasileiro de Educação em Engenharia. Fortaleza, CE: [s.n.]. 2019. p. 9. NTU. Programmes. NTU - Nanyang Technological University, 2020. Disponível em: http:// mae.ntu.edu.sg/Programmes/Pages/Home.aspx. Acesso em: 19 jan. 2020.

OECD. Results from PISA 2015 - Country Note: Brazil. OECD - Organisation for Economic Co-operation and Development. Paris. 2016.

OECD. The Future of Education and Skills - Education 2030. Organisation for Economic Co-operation and Development (OECD). Paris, France, p. 23. 2018.

OLIVEIRA, V. F. D. (. ). A Engenharia e as Novas DCNs: Oportunidades para formar mais e melhores engenheiros. Rio de Janeiro, RJ: GEN/LTC, 2019a. 
um panorama nacional e internacional

OLIVEIRA, V. F. D. As inovações nas atuais diretrizes para a Engenharia: estudo comparativo com as anteriores. Rio de Janeiro, RJ: GEN/LTC, 2019b. p. 66-85.

OLIVEIRA, V. F. D. Evolução da organização do curso de Engenharia no Brasil. In: OLIVEIRA, W. F. D. (. ). A Engenharia e as novas DCNs: Oportunidades para formar mais e melhores enhenheiros. Rio de janeiro, RJ: GEN/LTC, 2019c. p. 8-32.

PUC-CHILE. Major en Ingeniería, Diseño e Innovación. PUC - Pontifical Catholic University of Chile, 2020. Disponível em: Pontifical Catholic University of Chile. Acesso em: 19 jan. 2020. QS. QS World University Rankings by Subject 2019 - Engineering and Technology. QS - Quacquarelli Symonds Top Universities, 2020. Disponível em: https://www.topuniversities. com/university-rankings/university-subject-rankings/2019/engineering-technology. Acesso em: 12 jan. 2020.

SATHIKH, P. M. Approaches to Teaching Product Design to Engineering Students. In: DS 93: Proceedings of the 20th International Conference on Engineering and Product Design Education (E\&PDE 2018). Londres: [s.n.]. 2018. p. 648-655.

SU. Environmental Systems Engineering Program. SU - Stanford University, 2020. Disponível em: https://ughb.stanford.edu/majors-minors/major-programs/environmental-systems-engineering-program. Acesso em: 19 jan. 2020.

THE. World University Rankings 2019 by subject: engineering and technology. Times Higher Education (THE) World University Rankings, 2019. Disponível em: https://www.timeshighereducation.com/world-university-rankings/2019/subject-ranking/engineering-and-IT\#!/ page/0/length/25/sort_by/rank/sort_order/asc/cols/stats. Acesso em: 16 jan. 2020.

THE BALANCECAREERS. What Are Soft Skills? the balancecareers, 2020. Disponível em: https://www.thebalancecareers.com/what-are-soft-skills-2060852. Acesso em: 11 jan. 2020.

TSCHIMMEL, K.; SANTOS, J. Design Thinking Applied in Higher Education: D-Think, a European Project for Innovating Educational Systems. In: Proceedings of the International Conference on Education and New Developments (END 2018). Lisboa: inScience Press. 2018. p. 209-213.

U.S. NEWS. Best Global Universities for Engineering. U.S. News \& World Report Education, 2020. Disponível em: https://www.usnews.com/education/best-global-universities/engineering. Acesso em: 16 jan. 2020.

UNESCO. Engineering: issues, challenges and opportunities for development. UNESCO - United Nations Education, Scientific and Cultural Organization. Paris, France, p. 396. 2010. (ISBN 978-92-3-104156-3).

UT. EngSci Majors. UT - University of Toronto, 2020a. Disponível em: https://engsci.utoronto.ca/explore_our_program/majors/. Acesso em: 19 jan. 2020.

VERGANTI, R. Design Driven Innovation. Mudar as regras da competição: a inovação radical do significado de produtos. 2a ed. São Paulo: Canal Certo, 2012. 271 p.

VIANNA, M.; VIANNA, Y.; ADLER, I.; LUCENA, B.; RUSSO, B. Design Thinking: inovação em negócios. 2. ed. Rio de janeiro, RJ: MJV Press, 2012. $161 \mathrm{p}$.

ZUANON, R.; PRADO, G.; FERREIRA, C. Transdisciplinaridades. DATJournal Design Art and Technology, São Paulo, 1, n. 2, 2016. 1-27. Disponível em: https://datjournal.anhembi.br/ dat/article/view/36. Acesso em: 17 maio 2020.

Recebido: 17 de fevereiro de 2020 . Aprovado: 05 de maio de 2020 . 